\title{
Does nonstationarity in rainfall require nonstationary intensity-duration-frequency curves?
}

\author{
Poulomi Ganguli ${ }^{1, \mathrm{a}}$ and Paulin Coulibaly ${ }^{1}$ \\ ${ }^{1}$ Department of Civil Engineering, McMaster Water Resources and Hydrologic Modelling Group, McMaster University, \\ 1280 Main Street West, Hamilton, ON L8S 4L7, Canada \\ anow at: GFZ German Research Centre for Geosciences, Sect. 5.4 Hydrology, 14473 Potsdam, Germany
}

Correspondence: Poulomi Ganguli (poulomi.ganguli@alumnimail.iitkgp.ac.in, gangulip@mcmaster.ca)

Received: 7 June 2017 - Discussion started: 12 June 2017

Revised: 31 October 2017 - Accepted: 10 November 2017 - Published: 18 December 2017

\begin{abstract}
In Canada, risk of flooding due to heavy rainfall has risen in recent decades; the most notable recent examples include the July 2013 storm in the Greater Toronto region and the May 2017 flood of the Toronto Islands. We investigate nonstationarity and trends in the short-duration precipitation extremes in selected urbanized locations in Southern Ontario, Canada, and evaluate the potential of nonstationary intensity-duration-frequency (IDF) curves, which form an input to civil infrastructural design. Despite apparent signals of nonstationarity in precipitation extremes in all locations, the stationary vs. nonstationary models do not exhibit any significant differences in the design storm intensity, especially for short recurrence intervals (up to 10 years). The signatures of nonstationarity in rainfall extremes do not necessarily imply the use of nonstationary IDFs for design considerations. When comparing the proposed IDFs with current design standards, for return periods (10 years or less) typical for urban drainage design, current design standards require an update of up to $7 \%$, whereas for longer recurrence intervals (50-100 years), ideal for critical civil infrastructural design, updates ranging between $\sim 2$ and $44 \%$ are suggested. We further emphasize that the above findings need re-evaluation in the light of climate change projections since the intensity and frequency of extreme precipitation are expected to intensify due to global warming.
\end{abstract}

\section{Introduction}

Short-duration extreme rainfall events can have devastating consequences, damage to crops and infrastructures, leading to severe societal and economic losses in Canada (CCF, 2013; TRCA, 2013). In a warming climate, extreme precipitation events are expected to intensify due to moistening of the atmosphere (Donat et al., 2016; Fischer and Knutti, 2016; Pendergrass et al., 2015; Prein et al., 2016; Pfahl et al., 2017). Using observational records, a review of the literature suggests a dependency between mean and extreme precipitation on temperature (O'Gorman, 2015). The increased water-holding capacity of warmer air, as governed by the Clausius-Clapeyron $(\mathrm{C}-\mathrm{C}$ ) relation (Lenderink and van Meijgaard, 2008; O'Gorman and Schneider, 2009; Wasko and Sharma, 2015, 2017), intensifies heavy rainfall at a rate of approximately $7-8 \%{ }^{\circ} \mathrm{C}^{-1}$ of warming. On a local scale, for sub-hourly and up to 6-hourly extreme precipitation, increases at or above the $\mathrm{C}-\mathrm{C}$ rate have been found in the Netherlands (Lenderink and van Meijgaard, 2008; Lenderink et al., 2017), Switzerland (Ban et al., 2014), Germany (Berg et al., 2013), the UK (Blenkinsop et al., 2015), the Mediterranean (Drobinski et al., 2016), most of Australia (Wasko and Sharma, 2015, 2017; Schroeer and Kirchengast, 2017), North America (Shaw et al., 2011), and China (Miao et al., 2016), while in India (Ali and Mishra, 2017) and northern Australia (Hardwick Jones et al., 2010) negative rates have been reported. The extent of urbanization also contributes to extreme regional precipitation through the urban heat island effect and aerosol concentration (Dixon and Mote, 2003; Mölders and Olson, 2004; Guo et al., 2006; Mohsen and Gough, 2012; Wang et al., 2015). One of the first attempts 
to derive nonstationary IDF through the Bayesian inference (BI) approach for extreme value analysis was by Cheng and AghaKouchak (2014), where the authors introduced a linear trend in the parameters of the selected distribution. Agilan and Umamahesh (2017) used six physical processes, namely, time, urbanization, local temperature changes, the annual global temperature anomaly (as an indicator of global warming), El Niño-Southern Oscillation (ENSO), and the Indian Ocean Dipole (IOD) as covariates for the nonstationary extreme precipitation analysis in the city of Hyderabad, India. Their analysis indicated that the local processes, urbanization, and local temperature changes are the best covariates for short-duration rainfall, whereas global processes, such as global warming, the ENSO cycle, and IOD, are the best covariates for the long-duration rainfall. In their study, time was never qualified as the best covariate for modelling localscale extreme rainfall intensity. Singh et al. (2016) performed nonstationary frequency analysis of Indian Summer Monsoon Rainfall extreme (ISMR; defined as cumulative rainfall over continental India from 1 June to 30 September) and found evidence of significant nonstationarity in ISMR extremes in urbanizing or developing urban areas (transitioning from rural to urban), as compared to completely urbanized or rural areas. However, their analysis was performed at a spatial resolution of $1^{\circ}$ using gridded daily precipitation data obtained from the Indian Meteorological Department (IMD). Ali and Mishra (2017) showed that a strong (higher than the $\mathrm{C}-\mathrm{C}$ rate) positive relationship exists between shortduration rainfall extremes, dew point, and tropospheric temperature (T850; or the temperature in the upper troposphere at $850 \mathrm{hPa}$ ) over 23 urban locations in India. The latter two were subsequently used as covariates for nonstationary design storm estimates. The results indicated an increase in rainfall maxima at a majority of locations assuming nonstationary conditions over stationary atmospheric conditions. In contrast, in another studies, over Melbourne and Victoria, in Australia, Yilmaz et al. $(2014,2017)$ found superiority of stationary models over nonstationary models. To develop nonstationary models, the authors (Yilmaz et al., 2014, 2017) considered both the time dependency and dependency on large-scale climate oscillations affecting Australian rainfall. Using temperature as a covariate for nonstationarity, Wasko and Sharma (2017) investigated the sensitivity of extreme daily precipitation and streamflow to changes in daily temperature. Their results suggested a little evidence of an increase in streamflow, with an increase in heavy rainfall events at higher temperature.

However, most of these previous studies have analysed changes in expected point estimates of nonstationary vs. stationary design storm intensity (hereafter referred to as DSI), but have not reported the statistical significance of the difference between the two methods of estimates. To our best knowledge, no thorough comparison of stationary vs. nonstationary methods for deriving IDF statistics has been conducted in Southern Ontario, Canada. For densely populated
Southern Ontario, observations and multiple climate models suggest increasing trends in regional surface temperature and extreme precipitation in recent decades (Stone et al., 2000; Paixao et al., 2011; Mailhot et al., 2012; De Carolis, 2012; Burn and Taleghani, 2013; Shephard et al., 2014; Deng et al., 2016). A recent study shows an increase in local surface temperature of $3.06 \pm 0.18^{\circ} \mathrm{C}_{\text {century }}{ }^{-1}$ in the Greater Toronto Area (GTA) since the 1960s (Berkeley Earth, 2017). In July 2013, a single storm event has resulted in $126 \mathrm{~mm}$ of rainfall in the GTA, causing total insured losses of around USD 940 million, and is claimed to be the third-most expensive weather-related event in Canada (CDD, 2015; TRCA, 2013).

Extreme rainfall statistics are often mathematically expressed using the concept of exceedance probability or $T$ year return period (i.e. $T=1 /(1-F p(P))$, where $F p(P)$ is the cumulative probability of the underlying distribution), and graphically as a decision relevant metric in the form of intensity-duration-frequency (IDF) curves (or relations) (ASCE, 2006; CSA, 2010; EC, 2012). These curves are based on a comprehensive statistical analysis of historical rainfall records and are widely used for the design and operation of storm-water and sewerage systems, and other engineered hydraulic structures (Coulibaly and Shi, 2005; Durrans and Brown, 2001; Lima et al., 2016; Madsen et al., 2009; Rana et al., 2013; Sandink et al., 2016; Yilmaz et al., 2014a). At a given return period and storm duration, the average DSI is determined from the IDF relationship. The IDF curves are based on fitting a theoretical probability distribution to shortduration (sub-hourly, hourly, and daily) annual maximum precipitation (AMP). The approach can be implemented both locally (at site) or regionally (Svensson and Jones, 2010; regional frequency analysis (RFA) or pooled). The RFA is used when available record lengths are short or at locations where no observed data are available (Castellarin et al., 2012; Komi et al., 2016). However, various RFA estimation methods have certain drawbacks; for instance, the index flood method is sensitive to the homogeneity assumption and formation of regions; in a Bayesian method of regionalization, the prior distributions of parameters are often not precise enough and do not add precision to the estimates. Komi et al. (2016) summarize limitations and advantages of some of the widely used RFA techniques. In the present study, the available records across all sites range between 47 and 66 years, which are more than the climatology (often over time periods of 30 years) of a region. Therefore, we employ at-site frequency analysis herein. This also allows a consistent comparison with the Environment Canada (EC) IDFs that have been used in practice in the study area. For Canada, information for preparation of IDFs and nation-wide IDF curves is archived at the EC Engineering Climate Datasets (EC, 2014; http://climate.weather.gc.ca/prods_servs/engineering e.html), which is produced based on short-duration available rainfall records from the tipping-bucket rain gauges (TBRGs). Nevertheless, the methodology to derive existing 
IDF curves has certain drawbacks, for example that the current IDF curves in Canada are based on the assumption of stationarity, which implies that statistical properties of hydroclimatic time series will remain the same over the period of time. However, the impact of urbanization and humaninduced climate change (IPCC SREX, 2012; Villarini et al., 2009a; Milly et al., 2009; Kunkel, 2003) raises the question of whether the stationarity assumption to derive IDF curves is still reliable for urban infrastructural planning (Sarhadi and Soulis, 2017; Cheng and AghaKouchak, 2014; Jakob, 2013; Yilmaz et al., 2014a; Yilmaz and Perera, 2013).

The nonstationary behaviour of rainfall extremes is already being reflected in the increase in the frequency or magnitude of such events, resulting in a shift in its distribution (Figure SPM 0.3 in the IPCC SREX, 2012; Fig. S1 in the IPCC AR5 working Group Report, Stocker et al., 2013). For instance, seasonal and annual extreme precipitation in the northern-central and eastern US in 2013 (Knutson et al., 2014), extreme rainfall in the Golden Bay region in New Zealand (Dean et al., 2013), an increase in the summer precipitation rate in northern Europe (Yiou and Cattiaux, 2013), and successive winter storm events in southern England in 2013/14 leading to severe winter floods (Schaller et al., 2016) are primarily attributable to intrinsic natural variability and partly to anthropogenic influences. The asymmetric changes in the distribution of extremes owing to climate change have subsequently been validated for winter temperature extremes over the Northern Hemisphere (Kodra and Ganguly, 2014) and regional short-duration precipitation extremes in India and Australia (Mondal and Mujumdar, 2015; Westra and Sisson, 2011). Two of the recent studies (Deng et al., 2016; Mailhot et al., 2012) analysed a large ensemble of CMIP3 global climate model (GCM) runs and a sub-set of regional climate models that are part of the North American Regional Climate Change Assessment Program (NARCCAP) in terms of impact-relevant metrics over Canada. Both studies confirmed a relative increase in intensity and magnitude of rainfall extremes, especially over Southern Ontario. This issue has come to our attention in the Guideline for Canadian water resources practitioners (CSA, 2010), which urges the need for updated IDF calculations:

[...] climate change will likely result in an increase in the intensity and frequency of extreme precipitation events in most regions in the future. As a result, IDF values will optimally need to be updated more frequently than in the past $[. .$.$] .$

Furthermore, so far very few studies have reported the difference between the updated vs. EC-generated IDFs, taking into account nonstationarity in design consideration. Simonovic and Peck (2009) compared updated vs. EC IDFs for the city of London, Ontario, and reported that EC IDF curves show a difference of the order of around $20 \%$. However, their analysis was based on the stationarity assumption of precipitation extremes. Similarly, Coulibaly et al. (2015) have compared EC IDFs with stationary GEV-based IDF curves across Southern Ontario; however, no nonstationary methods were investigated. Motivated by these research gaps, here we address several important questions pertaining to shortduration precipitation extremes over Southern Ontario, to improve pro-active management of storm-induced urban flooding. First, is there any signature of statistically significant nonstationary trends (gradual or monotonic changes), change points, or regime shifts (occurrence of any abrupt changes in the mean/variance of the distribution) in short-duration AMP in densely and moderately populated urbanized locations across Southern Ontario? Second, does nonstationarity in the time series necessitate the use of nonstationary IDFs, barring economic consideration and the mathematical complexity involved in the design? Third, how can we use this knowledge to assess the credibility of existing EC-generated IDFs against the backdrop of a changing climate? We do not attempt to provide a methodological comparison of ECgenerated IDFs vs. the current approach, but will focus on differences in estimated DSI values between the updated and EC IDFs. Further, to this end, we test the hypothesis that signatures of nonstationarity in rainfall extremes do not necessitate the use of nonstationary IDFs for design considerations. In general, urban drainage areas have substantial proportions of impervious or semi-impervious land cover, which significantly reduce response time to extreme precipitation and increase the peak flow, resulting in storm-induced floods (Miller et al., 2014). Hence, it is the short-duration precipitation extremes which control the design of urban infrastructure (Mishra et al., 2012). Therefore, we focus our analysis on AMP intensity. We select Southern Ontario as a test bed because of the majority of stations with more than 30 years of available rainfall records (Adamowski and Bougadis, 2003; Deng et al., 2016; Shephard et al., 2014). Recent studies have indicated that the region is more vulnerable to climate change than any other part of Canada (Deng et al., 2016; Mailhot et al., 2012). Furthermore, Southern Ontario is one of the prominent economic hubs, with the largest population concentration in Canada (Bourne and Simmons, 2003; Kerr, 1965; Partridge et al., 2007). In this context, we explore a robust statistical framework to evaluate possible nonstationary trends, analyse the frequency of urban precipitation extremes, and assess the risk of severe rain-induced urban flooding in Southern Ontario (Table 1).

\section{Study area and data}

\subsection{Study area}

Southern Ontario is situated on a southwest-northeast transect, in the southernmost Canadian region, and is separated from the United States by lakes Erie, Huron, and Ontario (Fig. 1). The study area includes nine densely and moderately populated urbanized and anthropogenically altered locations 
Table 1. Selected station locations, population distribution, and hourly and daily data availability.

\begin{tabular}{|c|c|c|c|c|c|c|c|c|c|c|}
\hline Stations & $\begin{array}{r}\text { EC station } \\
\text { ID }\end{array}$ & Lat $\left({ }^{\circ}\right)$ & Long $\left({ }^{\circ}\right)$ & $\begin{array}{l}\text { Eleva- } \\
\text { tion }(\mathrm{m})\end{array}$ & $\begin{array}{r}\text { Population } \\
\text { estimate }\end{array}$ & $\begin{array}{l}\text { Census } \\
\text { Subdivision }\end{array}$ & $\begin{array}{l}\text { EC-derived } \\
\text { AMP }\end{array}$ & $\begin{array}{l}\text { Hourly } \\
\text { Rainfall }\end{array}$ & $\begin{array}{l}\text { Daily } \\
\text { Rainfall }\end{array}$ & $\begin{array}{l}\text { Missing years/ } \\
\text { Duration values }\end{array}$ \\
\hline Toronto P. Int'l Airport & 6158731 & 43.68 & -79.63 & 173.4 & 5583046 & Toronto $\mathrm{CMA}^{1}$ & 1950-2013 & 1960-2012 & 1940-2013 & $\begin{array}{l}1952-53,2005 \\
{[15-30 \mathrm{~min}, 1-6 \mathrm{~h}]}\end{array}$ \\
\hline Hamilton Airport & 6153194 & 43.17 & -79.93 & 237.7 & 519949 & Population centre & $1971-2003$ & $1971-2003$ & 1960-2010 & $2004-2010$ \\
\hline Oshawa WPCP & 6155878 & 43.87 & -78.83 & 83.8 & 356177 & Oshawa CMA & 1970-2006 & 1970-1999 & 1970-2015 & $\begin{array}{l}1971[15-30 \mathrm{~min}, \\
1-6 \mathrm{~h}], 1995[12 \mathrm{~h}], \\
1999[6-12 \mathrm{~h}], \\
2000,2005-06 \\
{[15-30 \mathrm{~min}, 1-6 \mathrm{~h}],} \\
2007-15\end{array}$ \\
\hline Windsor Airport & 6139525 & 42.28 & -82.96 & 189.6 & 319246 & Windsor CMA & $1946-2007$ & 1960-2007 & 1940-2013 & $1950,2008-2013$ \\
\hline Kingston P. Station & 6104175 & 44.24 & -76.48 & 76.5 & 159561 & Kingston CMA & 1961-2007 & $1961-2003$ & 1960-2007 & 2004 \\
\hline London Int'l Airport & $6144478 / 75^{2}$ & 43.03 & -81.15 & 278 & 474786 & London CMA & $1950-2007^{2}$ & $1961-2001$ & $1940-2015$ & $\begin{array}{l}1950-51,2002, \\
2008-2015\end{array}$ \\
\hline Trenton Airport & 6158875 & 44.12 & -77.53 & 86.3 & 43086 & Population centre & $1965-2013$ & 1964-1997 & $1935-2015$ & $\begin{array}{l}1974,1998-99, \\
2002[15-30 \mathrm{~min}, \\
1-6 \mathrm{~h}], 2003-04\end{array}$ \\
\hline Stratford WWTP & 6148100 & 43.37 & -81.0 & 345 & 30886 & $\mathrm{CA}$ & 1966-2004 & $1966-2007$ & 1960-2015 & 1973,1999 \\
\hline Fergus Shand Dam & 6142400 & 43.73 & -80.33 & 417.6 & 19126 & Population centre & $1961-2007$ & $1960-2007$ & $1950-2015$ & $\begin{array}{l}\text { 1969, 1971, 1986, } \\
1987,[2-6 \mathrm{~h}], \\
1992[6-12 \mathrm{~h}], \\
1995\end{array}$ \\
\hline
\end{tabular}

${ }^{1}$ CMA and CA denote census metropolitan area and census agglomeration respectively. Statistics Canada defines a CMA as having a population density of at least 100000 , where the urban core of that area has at least 50000 people, whereas CA must have an urban core population density of at least 10000 . A population centre (or urban area) is an area with at least a population of 1000 and a density of 400 or more people per square kilometre. All population information is collected from the Statistics Canada (https://www 12 .statcan.gc.ca/) website. ${ }^{2}$ Missing values are infilled using observations from the nearest Environment Canada
longitude $-81.5^{\circ}$ ), located at $111.5 \mathrm{~km}$ geodesic distance. Annual maxima values of missing years or durations are obtained by disaggregating daily data to hourly and sub-hourly time steps.
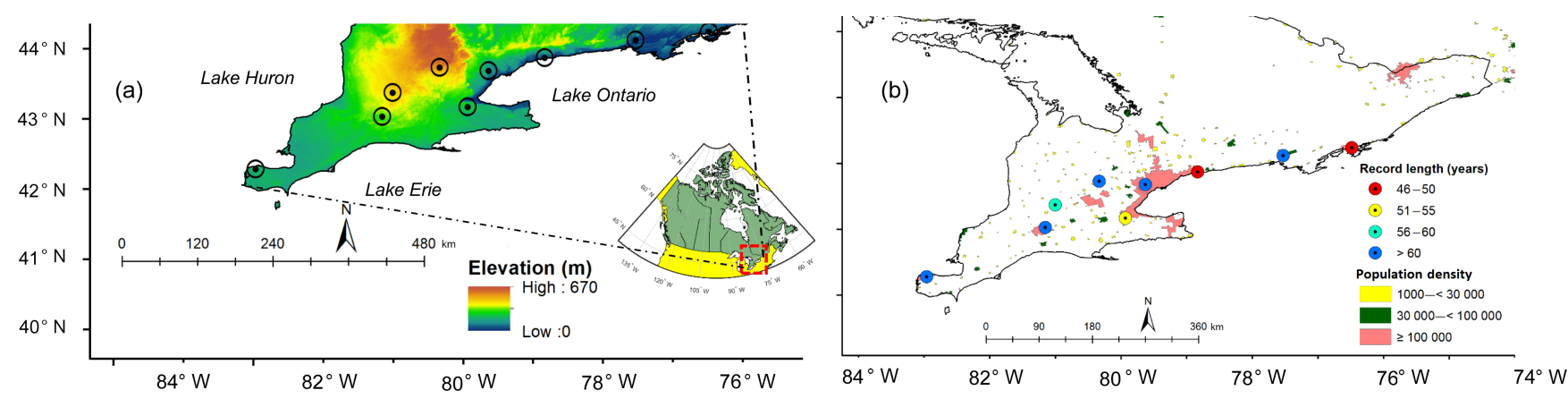

Figure 1. (a) Selected urbanized sites in Southern Ontario. Southern Ontario $\left(41-44^{\circ} \mathrm{N}, 84-76^{\circ} \mathrm{W}\right)$ is the southernmost region of Canada and is situated on a southwest-northeast transect, bounded by lakes Huron, Erie, and Ontario. The nine locations on the map are (from the southwestern to northeastern corner): Windsor Airport, London International Airport, Stratford Wastewater Treatment Plant (WWTP), Fergus Shand Dam, Hamilton Airport, Toronto International Airport, Oshawa Water Pollution Control Plant (WPCP), Trenton Airport, and Kingston Pumping Station. Topography map indicates the maximum slope of $670 \mathrm{~m}$ above mean sea level. (b) The population map shows six of the the sites: Windsor Airport, London International Airport, Hamilton Airport, Toronto International Airport, Oshawa WPCP, and Kingston P. Station are located either in or the vicinity of densely populated urbanized area. The remaining three sites are located in the moderately populated area. The short-duration AMP records in all locations vary between the minimum of 46 years and the maximum of 66 years.

of the Windsor-Kingston corridor (Fig. 1; Table 1). The last column in Table 1 shows a list of missing years and AMP values for each duration at each station. The digital elevation model (DEM) of the study area was derived from the Shuttle Radar Topography Mission (SRTM) 90 m Digital Elevation Database v4.1 (Jarvis et al., 2008), which indicates a shallow slope with a maximum altitude of $670 \mathrm{~m}$ above mean sea level (MSL). The proximity to Great Lakes and topographic effect, especially in areas to the lee of Lake Erie, Lake Ontario, and the Georgian Bay significantly modifies the climate in the region (Baldwin et al., 2011). Convective show- ers and thunderstorms primarily modulate the summer rainfall, but fall rainfall is dominated by reduced convective activity and increased lake effect precipitation (Lapen and Hayhoe, 2003). Further, the topographic features and associated westerly winds in the Niagara Escarpment and the Oak Ridge Moraine play a significant role in modulating rainfall in the Toronto region. On the other hand, the Windsor metropolitan area, the southernmost urbanized location in the region, has a humid continental climate, which results in warm summer temperatures $\left(30^{\circ} \mathrm{C}\right.$ or higher), with the greatest precipitation in the spring and summer seasons, and lowest in the 


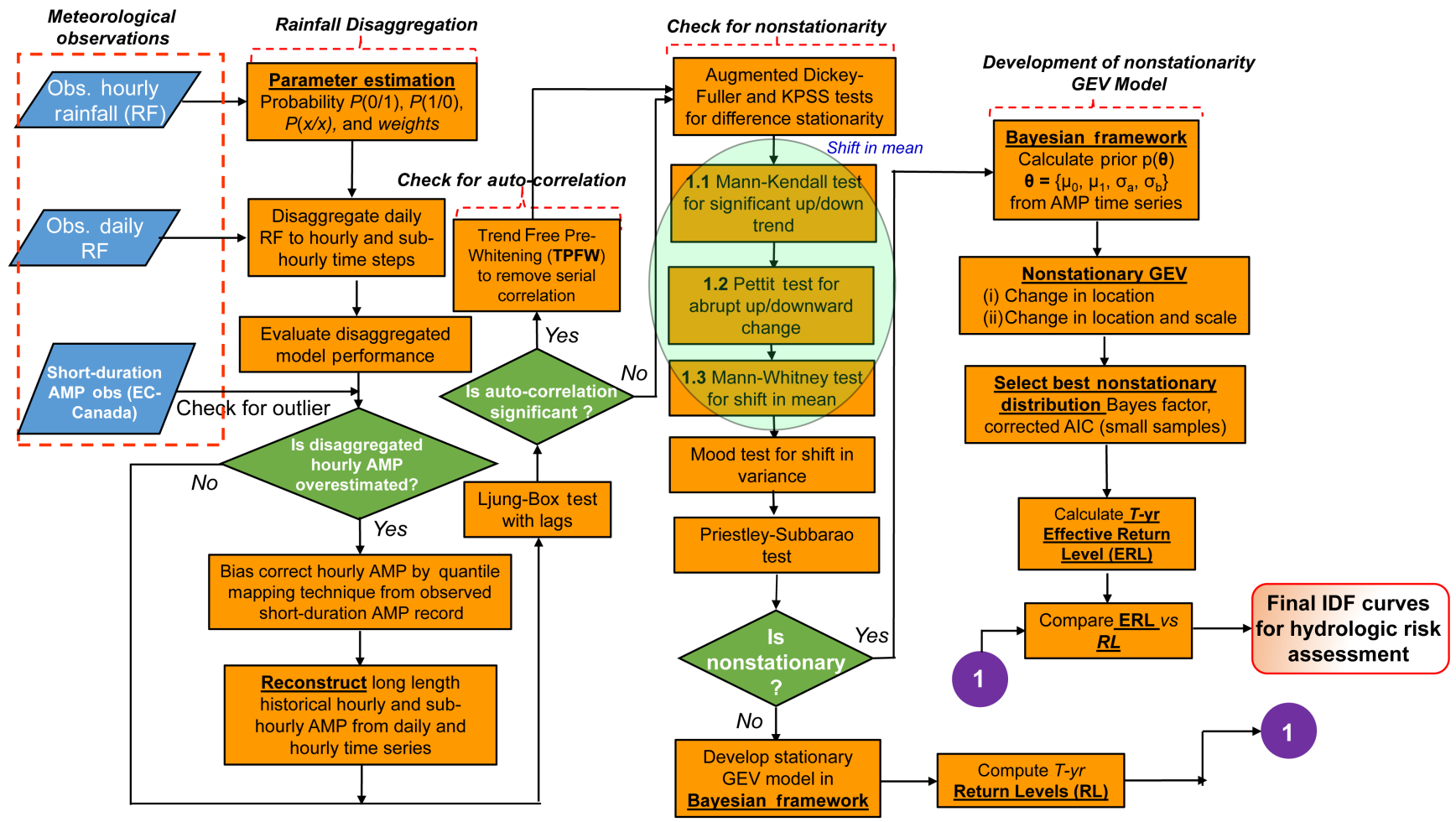

Figure 2. Schematics of the process flow (blue - input steps, orange - process steps, and green - decision steps). All three tests - MannKendall, Pettitt, and Mann-Whitney - check for shifts in the mean. While Mann-Kendall checks for monotonic trends, the other two tests, Pettitt and Mann-Whitney, check for a change point or regime shift in the time series.

autumn and winter (Sanderson and Gorski, 1978). Moreover, because of the part of Windsor-Detroit international transborder agglomeration, the extreme summer precipitation in the city of Windsor is primarily influenced by convection and urban heat island effect (Sanderson and Gorski, 1978; De Carolis, 2012).

\subsection{Hydrometeorological data}

We identified the station locations (Fig. 1b) based on the quality of long-range rainfall records (e.g. 30 years or more) and 2011 Census information archived at the Statistics Canada (SC, 2016) website (https://www12.statcan.gc.ca). The geographic areas of these locations are extracted from 2011 Census digital boundary shape files (https://www12.statcan.gc.ca/census-recensement/ 2011/geo/bound-limit/bound-limit-2011-eng.cfm).

The Toronto metropolitan area is the most populous (over 5 million in population) and known to be one of the fastest growing population bases in Canada (http://torontosvitalsigns.ca/main-sections/demographics/), while Fergus is the least populated (population of around 19000) (Table 1) city. The other cities have population ranges between $\sim 500000$ (Hamilton) and 30000 (Stratford) (Table 1). We obtained AMP observations at particular durations (15 and $30 \mathrm{~min}, 1,2,6,12$, and $24 \mathrm{~h}$ ) with a few data gaps from Engineering Climate Datasets archived and maintained by the EC (EC, 2014; http: //climate.weather.gc.ca/prods_servs/engineering_e.html).

The rainfall records collected from TBRG are thoroughly quality controlled (Shephard et al., 2014). These records have been previously analysed for the assessment of national extreme rainfall trends (Burn and Taleghani, 2013; Shephard et al., 2014). We consider seven storm durations ranging from 15 and $30 \mathrm{~min}$ (the typical time of concentration for small urban catchments) to $1,2,6,12$, and $24 \mathrm{~h}$ (the standard time of concentration for larger watersheds) following a previous study (Bougadis and Adamowski, 2006). Except for a few stations (for example, Toronto International Airport and Trenton Airport), for most of the sites, the AMP observation is available either until the year 2007 or before (Table 1). Also, we found missing values in the AMP time series in all sites. We obtained daily and hourly rainfall records from Environment and Climate Change Canada (ECCC, 2017).

\section{Methods}

Figure 2 shows schematics of the overall analysis. In the subsequent subsection, we will discuss each of these steps in detail. 


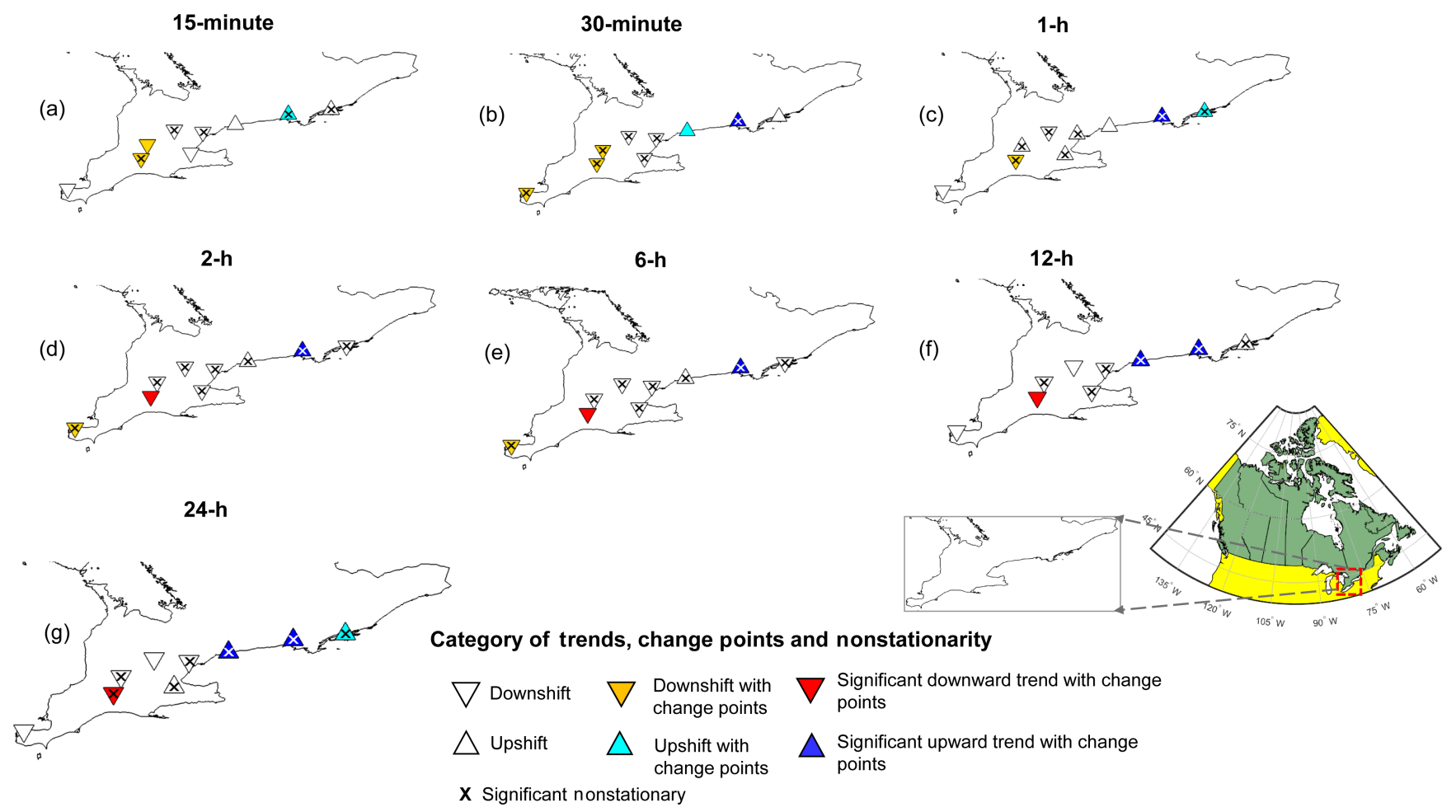

Figure 3. Spatial distribution of trends, change points, and nonstationarities in rainfall extremes of several durations in nine urbanized locations, Southern Ontario (a-g). The up and down triangles in white indicate (statistically insignificant) upward and downward shifts; the up and down triangles in cyan and orange indicate shifts with change points only; the up and down triangles in dark blue and red show the presence of (statistically significant) trends, including change point(s). A " $x$ " symbol in the triangle indicates nonstationarity detected through Priestley and Subbarao test statistics. All tests are performed at $10 \%$ significance levels, i.e. $p$ value $<0.10$.

\subsection{Infilling missing AMP record}

We infilled missing values and updated the AMP records by successively disaggregating daily rainfall values to hourly and sub-hourly time steps using a multiplicative random cascade (MRC)-based disaggregation tool. The cascade-based disaggregation model for continuous rainfall time series was suggested by (Olsson, 1995, 1998). The technique was later successfully implemented by (Güntner et al., 2001; Jebari et al., 2012; Rana et al., 2013) for temporal disaggregation of point rainfall and the development of IDF curves from shortduration rainfall extremes. Due to freezing weather conditions during winter, most of the TBRGs' are inoperative from early November to late April of the following year. Therefore, when short-duration rainfall records were not available, the AMP values over moving windows of $n$ durations ( $n$ varies from 15 to $30 \mathrm{~min}$, and between 1, 2, 6, 12, and $24 \mathrm{~h}$ ) are extracted from May to October (warm season) disaggregated rainfall volumes for remaining years. There are several reasons for selecting warm periods: first, extreme rainfall events mostly occur in the study area during the warm season (Cheng et al., 2010); second, the focus of our analysis is an investigation of extreme rainfall related flood risks and development of IDF curves using extreme rainfall statistics. We adjusted the occasional overestimation of extreme values at a higher order cascade step by a statistical post-processing method. We employed the quantile matching (QM) approach ( $\mathrm{Li}$ et al., 2010), which claims to outperform other simple bias correction methods and which corrects not only the mean, but also the variance of the distribution of interest (Gudmundsson et al., 2012; Teutschbein and Seibert, 2012). QM is based on equidistant cumulative probability distribution matching of observed and disaggregated AMP time series using a three-parameter generalized extreme value (GEV) distribution. Although like other statistical post-processing techniques, QM relies on the stationarity assumption of the time series, in our case, we applied QM to entire time series of both observed and disaggregated AMP, which comes from the same station location (or similar spatial resolution) and a similar period. Therefore, we avoid potential consequences of inflation by quantile mapping (Maraun, 2013) in our analysis. We discuss the implementations of MRC, adjustment of extremes, and associated model fits in more detail in the Supplement (Sect. S1). 

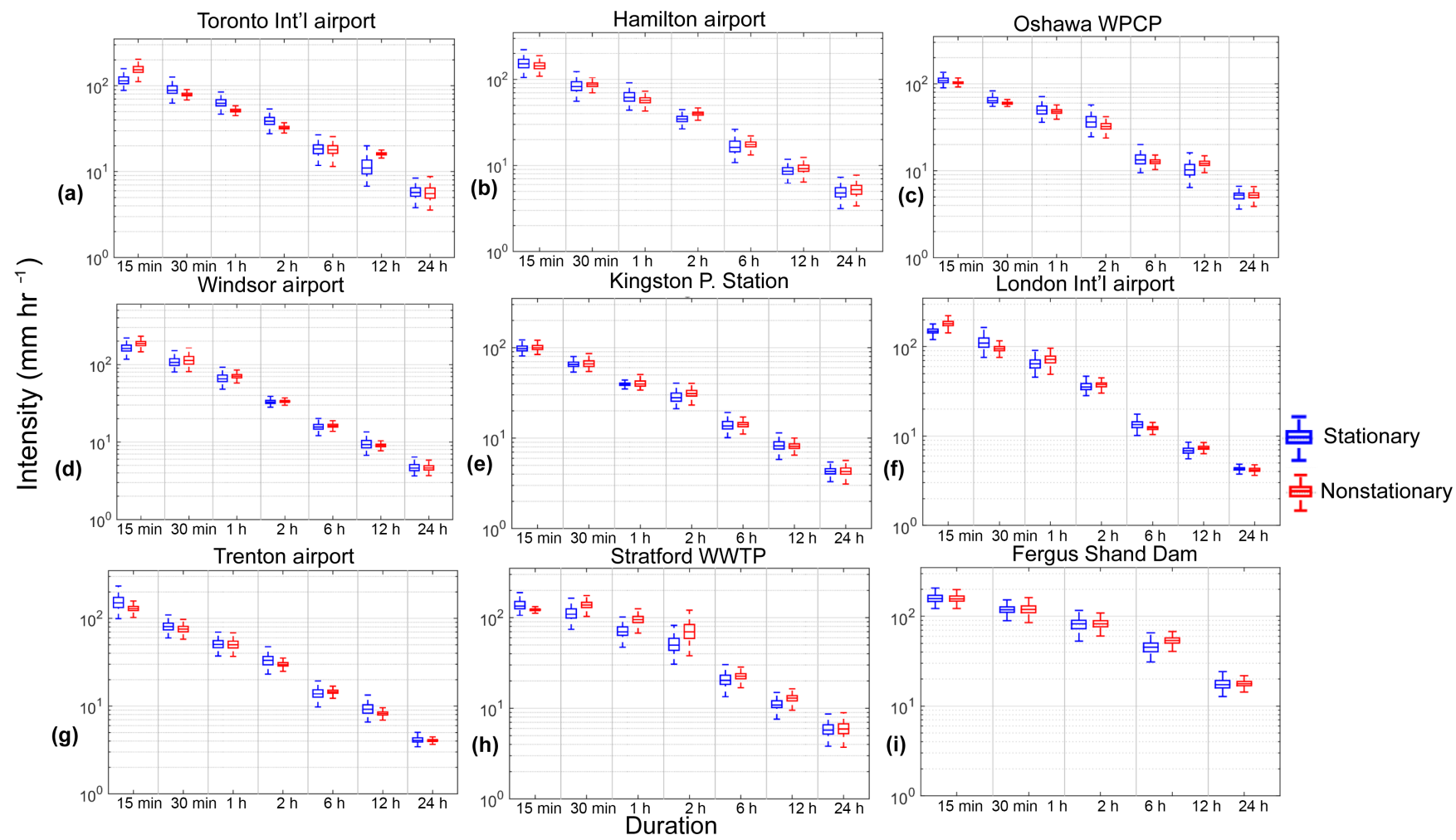

Figure 4. DSI estimates of the median (horizontal line within the box plot) and $95 \%$ credible intervals for 100-year return periods of stationary vs. nonstationary models across nine sites $(\mathbf{a}-\mathbf{i})$. The boxplots indicate the uncertainty in estimated DSI using Bayesian inference.

\subsection{Detection of nonstationarity}

A series of statistical tests are employed to detect the presence of nonstationary trends and abrupt shifts in the shortduration AMP before frequency analysis. The multiple tests allow a more rigorous and comprehensive assessment of the overall trend in the time series since certain tests are complementary to each other (Sadri et al., 2016; Yilmaz et al., 2014, 2017). Figure 2 shows the schematics of the overall analysis. Most of the trend and change-point detection algorithms assume observations are mutually independent. The presence of autocorrelations in the time series overestimates or underestimates the statistical significance of trend and change-point detection algorithms (Serinaldi and Kilsby, 2016; von Storch and Navarra, 1999). We employed a LjungBox test with 20 lags to the short-duration AMP time series at each site to check whether they show statistically significant autocorrelation (at the 5 and $10 \%$ significance levels). For the time series with no serial autocorrelation, we test for trending behaviour and nonstationarity. It is also important to note that the presence of nonstationarity may not be evaluated merely on the basis of trends or abrupt shifts in the time series, even if the increasing or decreasing trends are statistically significant (Yilmaz et al., 2014). First, we check for the presence of nonstationarity in the time series by employing a unit root-based augmented Dickey-Fuller
(ADF; Dickey and Fuller, 1981) test. However, the test may have a low power against stationarity near unit root processes (Dritsakis, 2004; Chowdhury and Mavrotas, 2006). Therefore, as a complement to the unit root test, a KPSS test (Kwiatkowski et al., 1992) is employed to validate the results of the ADF test. Since both the ADF and KPSS tests assume linear regression or normality of the distribution, alternatively, a log transformation can convert a possible exponential trend present in the data into a linear trend. Therefore, following previous studies (Gimeno et al., 1999; Van Gelder et al., 2006), the AMP time series is log-transformed before applying stationarity tests. However, Yilmaz et al. (2014) did not observe the presence of any significant nonstationarity in extreme rainfall time series in the city of Melbourne, even after employing ADF and KPSS tests. Therefore, as an alternative, we also employed a frequency-based Priestley and Subbarao test ("PSR" test; Priestley and Rao, 1969), which is able to better capture the nonlinear dynamical nature of a hydrological system than the former two tests (Ali and Mishra, 2017; Hamed and Rao, 1998). Next, we detected the presence of smooth and abrupt changes in the time series. The continuous or monotonic trends in short-duration rainfall extremes are identified using non-parametric MannKendall trend statistics with correction for ties (Hamed and Rao, 1998; Reddy and Ganguli, 2013) at the 5 and $10 \%$ significance levels. In general, the abrupt change (or change 


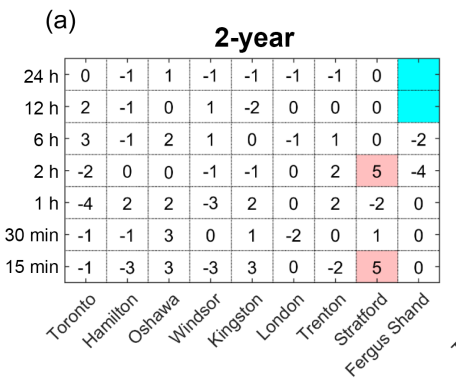

(b)

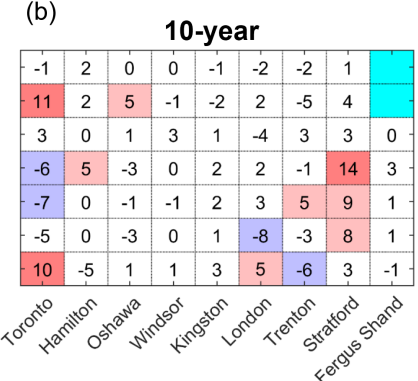

(c)

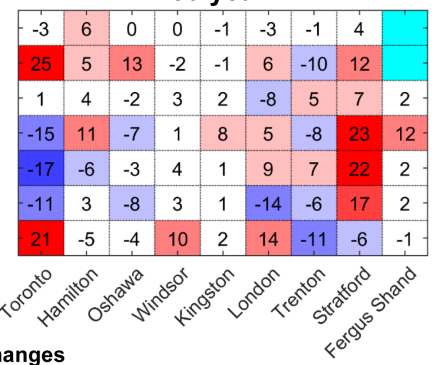

(d)

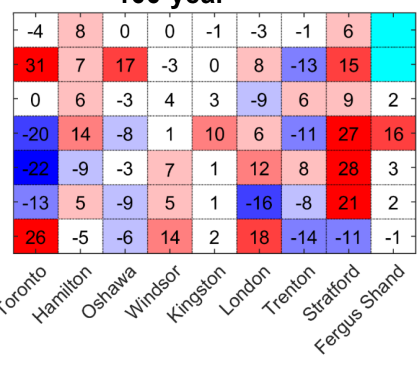

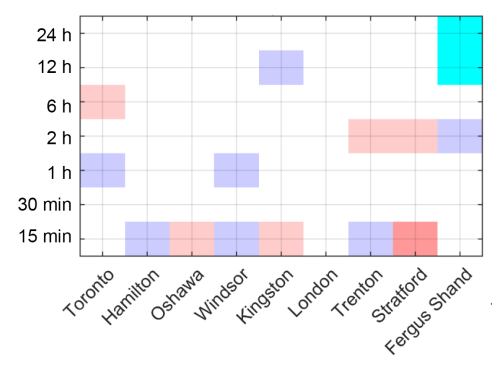

\begin{tabular}{lllllllllll}
\hline & & 1 & 1 & 1 & 1 & 1 & 1 & & & \\
-20 & -15 & -10 & -5 & 0 & 5 & 10 & 15 & 20 & 25 & 30
\end{tabular}
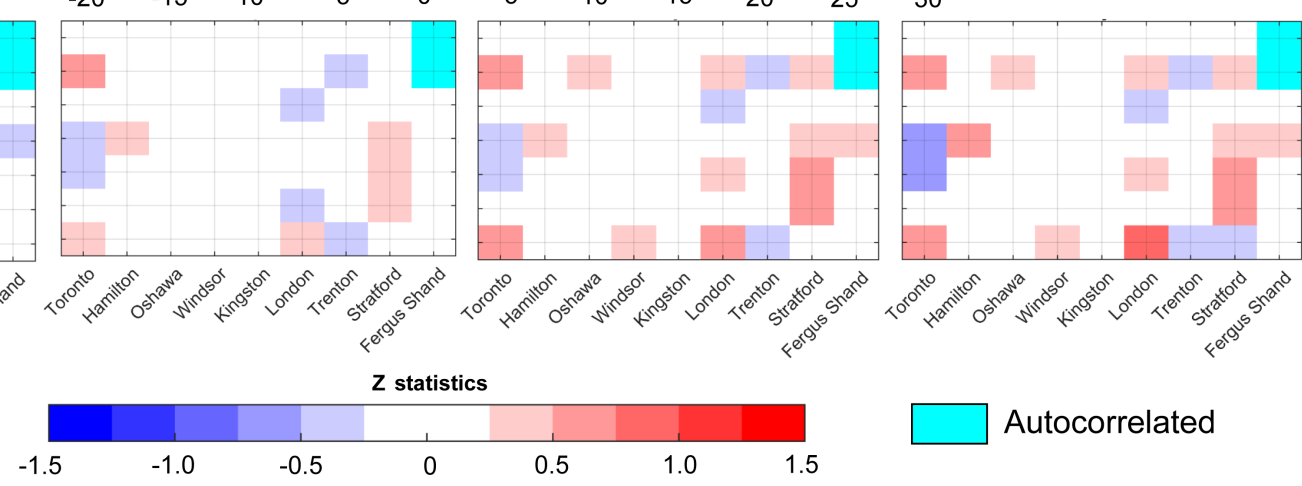

Z statistics

0 0.5 1.0 1.5

Autocorrelated

Figure 5. Percentage changes (top panel) and $Z$ statistics (bottom panel) of at-site $T$-year event estimates for $T=2$-year to $T=100$-year return periods (a-d) with durations between $15 \mathrm{~min}$ and $24 \mathrm{~h}$ in nine urbanized locations, Southern Ontario. The $Z$ statistic represents the statistical significance of differences in DSI obtained from the best selected nonstationary vs. stationary model. The $Z$ statistic is statistically significant when $|Z|>1.64$ at the $10 \%$ significance level. The shades in blue and red denote decrease and increase in $Z$ statistics, with the strength of the shading representing the magnitude of the test statistics. The durations with significant autocorrelations are excluded from the analysis.

point) in the time series occurs at a single point in the record and bifurcates the time series into two halves, either with different means or variances, or both dissimilar means and variance together at each part. The change point in the location (or mean) is identified using non-parametric Pettit (Pettitt, 1979) and Mann-Whitney tests (Ross et al., 2011). As indicated by previous studies (Xie et al., 2014; Yue and Wang, 2002), the rank-based nonparametric Mann-Whitney test is not really distribution-free, and the power of the test is often affected by the properties of sampled data. In practice, when a real change point is unknown, often a Mann-Whitney test, in general, does not work well, and the Pettitt method can yield a plausible change-point location along with its statistical significance. However, the significance of the Pettitt test can be obtained using an approximated limiting distribution (Xie et al., 2014; Sect. S2). The shift in scale (or variance) is detected using a non-parametric Mood test (Ross et al., 2011; see Fig. 2 for details). We applied nonparametric tests due to their robustness to non-normality, which usually appears in the hydroclimatic time series. Further, in order to reduce the number of underlying assumptions required for testing a hypothesis, such as the presence of a specific kind of trend or change point in the data, nonparametric tests are employed. For the time series with significant autocorrelation, we employed a trend-free pre-whitening procedure (TPFW; Sect. S2) as described in Yue et al. $(2002,2003)$ and later modified by Petrow and Merz (2009). Then, we applied trend and change-point detection algorithms to the pre-whitened AMP extremes. In order to test the issue of multiple comparisons associated with statistical analysis, we analysed $p$ values of five statistical tests, i.e. a Ljung-Box test, a KPSS test, a Mann-Kendall trend test, a PriestleySubbarao test, and a Pettitt test using the false discovery rate (FDR) method (not shown here) as suggested by Benjamini and Hochberg (1995). However, we excluded ADF, MannWhitney, and Mood tests from the analysis, since unlike other tests, the higher $p$ value in ADF statistics indicates the presence of nonstationarity in the time series. On the other hand, the latter two tests do not offer any $p$ values.

\subsection{Extreme value analysis of sub-daily and daily precipitation extremes}

Nationwide EC IDF curves were developed using a particular family of distribution functions from extreme value theory (i.e. a Gumbel distribution or extreme value type I, hereafter referred to as EVI). However, the EV1 distribution has cer- 

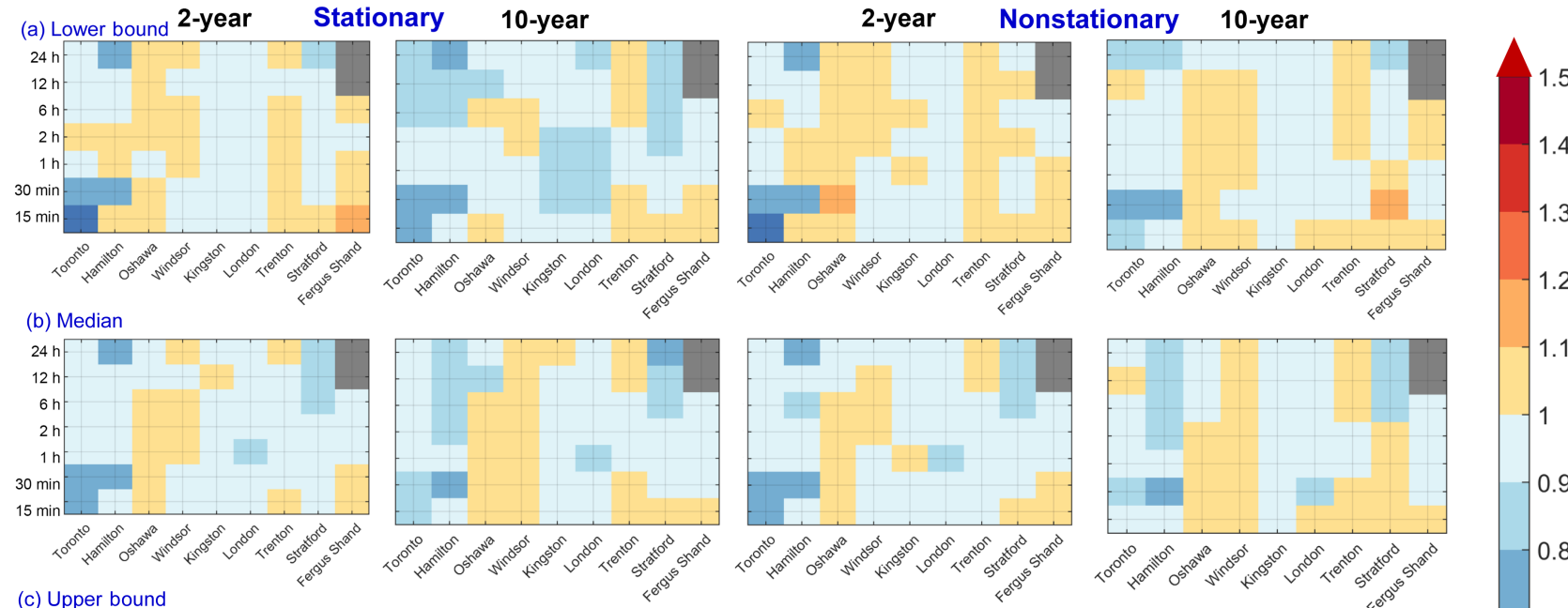

(c) Upper bound
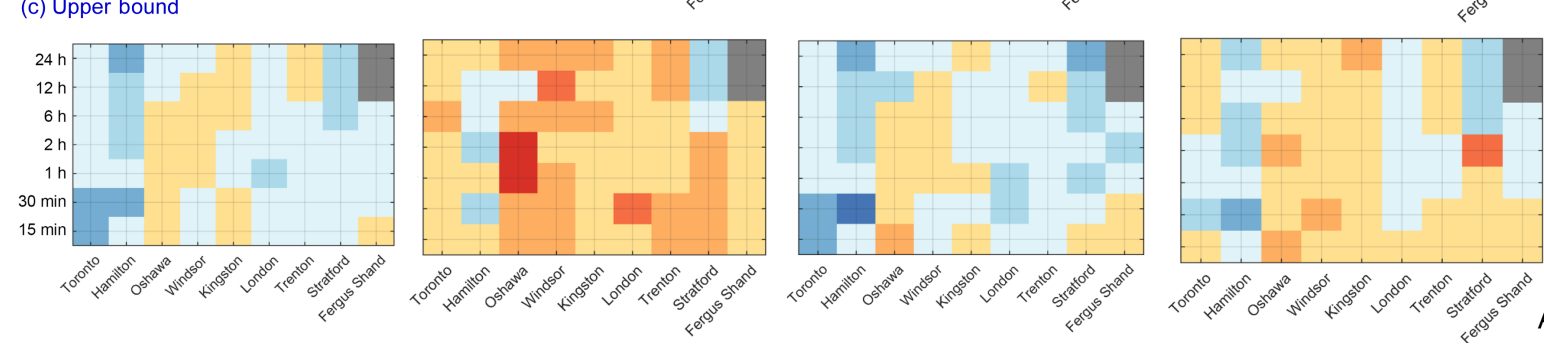

Figure 6. Central tendency (median, b) and the bounds (95\% credible interval, a and c) of the updated nonstationary vs. EC-generated $T=2$ - and 10-year event estimates for DSI at selected return periods with durations between $15 \mathrm{~min}$ and $24 \mathrm{~h}$. The DSI and associated $95 \%$ confidence limits of EC-generated IDF are obtained from the national archive of Engineering Climate Datasets (http://climate.weather.gc.ca/). The shades in blue and red denote decrease and increase in DSI. The strength of the shading represents the magnitude of the ratio between updated and EC-generated DSI.

tain limitations, such as that it is a non-heavy-tailed distribution and is characterized by constant skewness and kurtosis coefficients (Markose and Alentorn, 2005; Pinheiro and Ferrari, 2016). However, the short-duration AMP intensities often exhibit fat-tailed behaviour, indicating large skewness and kurtosis. In fact, a few studies in the past have shown that EV1 fits poorly to the historical rainfall extremes (Burn and Taleghani, 2013; Coulibaly et al., 2015). Therefore, in the present study, we perform frequency analysis of extreme precipitation using a GEV distribution. The choice of the GEV distribution was based on previous studies where various distribution functions were compared in the study area (Coulibaly et al., 2015; Switzman et al., 2017). The GEV distribution is a combination of the Gumbel, Fréchet, and Weibull distributions and is fitted to block or AM time series (Cheng and AghaKouchak, 2014; Katz et al., 2002; Katz and Brown, 1992). The GEV distribution is characterized by three parameters, the location, the scale, and the shape of the distribution, which describes the centre of the distribution, the deviation around the mean, and the shape or the tail of the distribution (Katz et al., 2002; Katz and Brown, 1992). The cumulative distribution function of the stationary (timeinvariant) GEV model is given by Coles et al. (2001) and
Gilleland and Katz (2016):

$G(z)= \begin{cases}\exp \left\{-\left[1+\zeta\left(\frac{z-\mu}{\sigma}\right)\right]_{+}^{-1 / \zeta}\right\} & \text { if } \zeta \neq 0 \\ \exp \left\{-\exp \left(-\frac{z-\mu}{\sigma}\right)_{+}\right\} & \text {if } \zeta \rightarrow 0\end{cases}$

where $y_{+}=\max \{y, 0\}$ and

$z \in[(\mu-\sigma) / \zeta,+\infty)$ when $\zeta>0$,

$z \in(-\infty,(\mu-\sigma) / \zeta]$ when $\zeta<0$, and

$z \in(-\infty,+\infty)$ when $\zeta=0$.

$\mu$ is a location parameter, $\sigma$ is a scale parameter and $\zeta$ is a shape parameter determining the heaviness of the tail. The shape parameter $\zeta$ determines the higher moments of the density function and also the skew in the probability mass. The "+" sign indicates the positive part of the argument. Equation (1) encompasses three types of DFs based on the sign of the shape parameter, $\zeta$ : (i) the Fréchet, with a finite lower bound of $(\mu-\sigma) / \zeta$ and an unbounded, heavy upper tail, $(\zeta>0)$, (ii) the Weibull, unbounded below and with a finite upper bound of $(\mu-\sigma) / \zeta,(\zeta<0)$, and (iii) the Gumbel, unbounded below and above with a light upper tail $\zeta=0$, formally obtained by taking the limit as $\zeta \rightarrow 0$. The Gumbel 


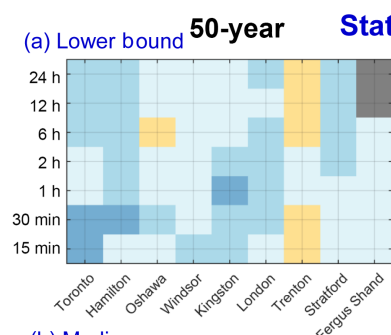

(b) Median
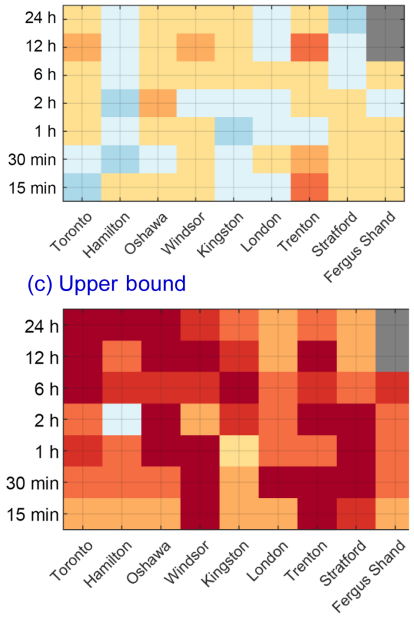
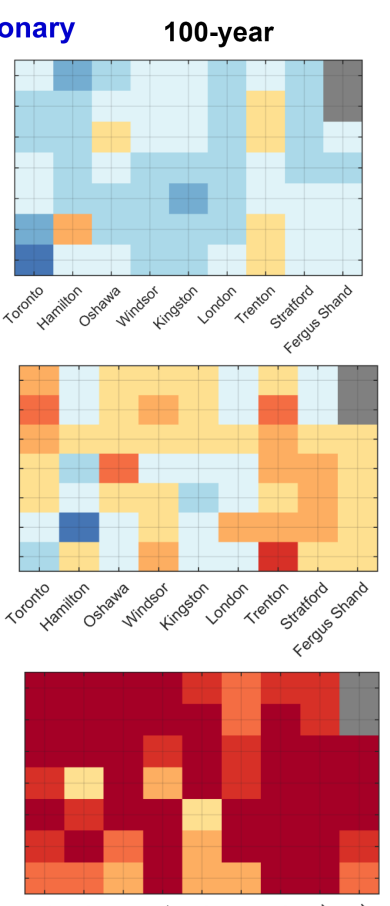

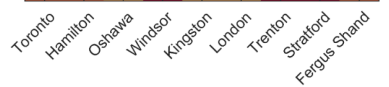
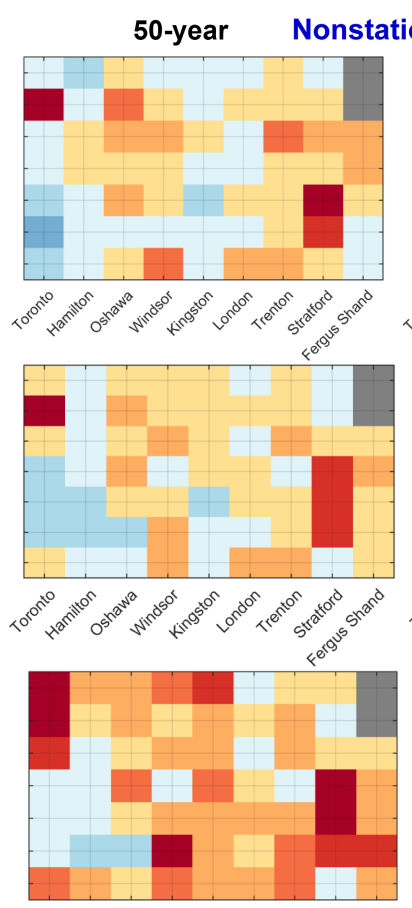

कर

\section{0-year}
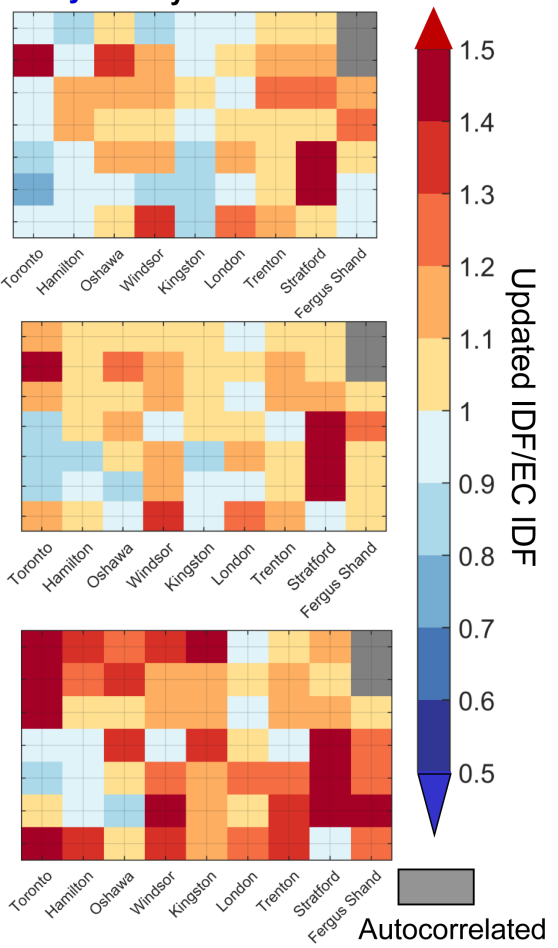

Figure 7. Central tendency (median, b) and the bounds (95\% credible interval, a and c) of the updated nonstationary vs. EC-generated $T=50$ - and 100-year event estimates for DSI at selected return periods with durations between $15 \mathrm{~min}$ and $24 \mathrm{~h}$. The DSI and associated $95 \%$ confidence limits of EC-generated IDFs are obtained from the national archive of Engineering Climate Datasets (http://climate.weather. gc.ca/). The shades in blue and red denote decrease and increase in DSI. The strength of shading represents the magnitude of the ratio between updated and EC-generated DSI.

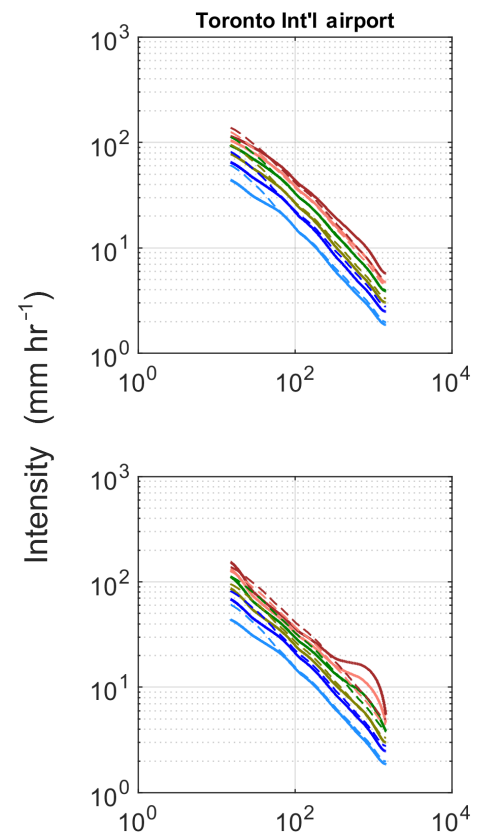

Updated IDF 5 -yr $-10-\mathrm{yr}-25-\mathrm{yr}-50-\mathrm{yr}-100-\mathrm{yr}$
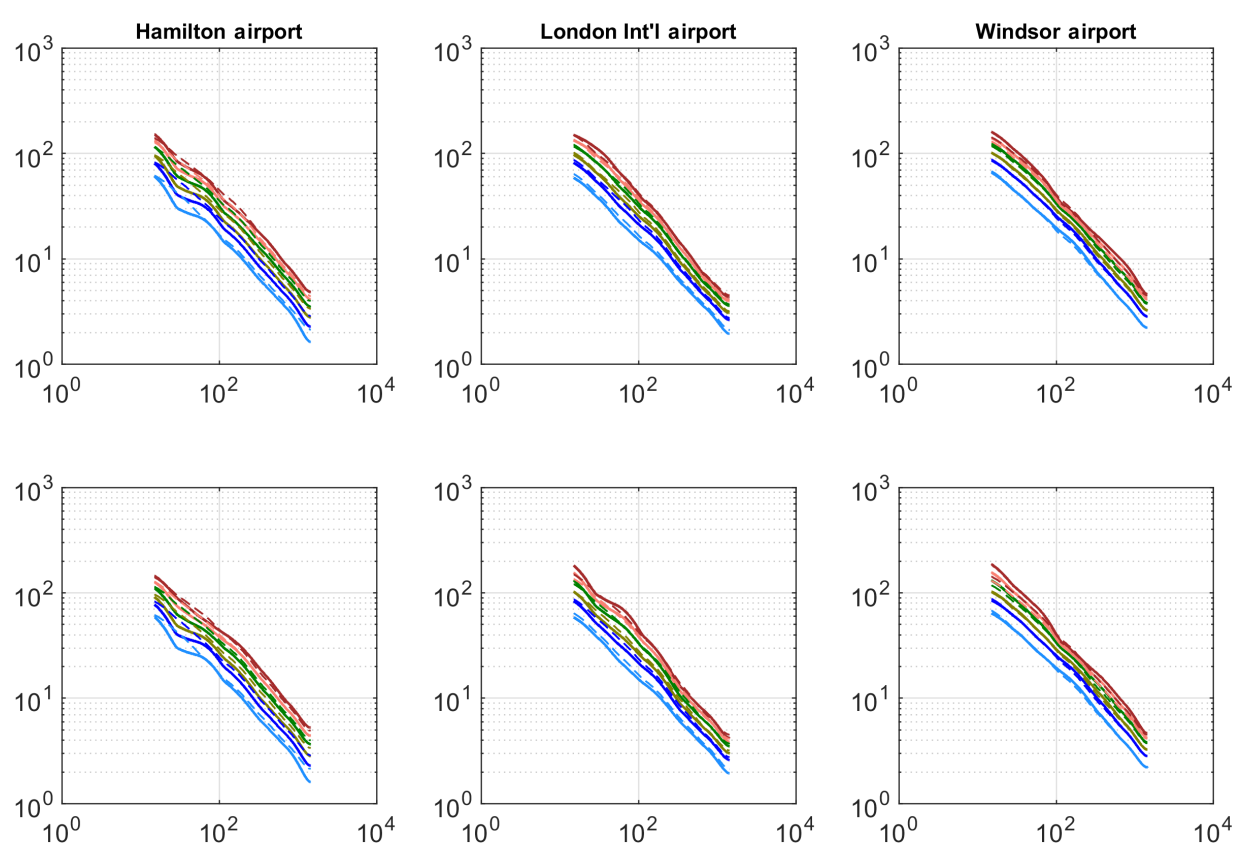

Duration (min)

Figure 8. Estimated nonstationary vs. EC-generated IDFs for $T=2-, 5-, 10-, 25-$, 50- and 100-year return periods for the selected urbanized locations in Southern Ontario, Canada. The updated and EC IDFs are shown using solid and dotted lines respectively. 
distribution is described by an unbounded light-tailed distribution and the tail decreases rapidly following an exponential decay. The Fréchet distribution is a heavy-tailed distribution, and the tail drops relatively slowly following a polynomial decay (Towler et al., 2010). On the other hand, the Weibull distribution is a bounded distribution. Here we compare the performance of both the stationary and nonstationary forms of the GEV distribution. For stationary models, we estimate parameters using BI coupled with a differential evaluation Markov chain (DE-MC) Monte Carlo (MC) simulation as suggested by Cheng et al. (2014) and Cheng and AghaKouchak (2014). For nonstationary models, the shape parameter is assumed constant throughout. Here it should be noted that modelling temporal changes in $\zeta$ requires long-term observations, which are often not available in practice (Cheng et al., 2014). Hence, following previous studies (Cannon, 2010; Cheng et al., 2014; El Adlouni et al., 2007; Gu et al., 2017), we incorporate time-varying covariates into GEV location $\left(\mathrm{GEV}_{t}-\mathrm{I}\right)$, and into both location and scale parameters $\left(\mathrm{GEV}_{t}\right.$-II) respectively, to describe trends as a linear function of time (in years):

$$
\begin{aligned}
\mu(t) & =\mu_{1} t+\mu_{0} \\
\sigma(t) & =\sigma_{1} t+\sigma_{0}
\end{aligned}
$$

Since the scale parameter must be positive throughout, it is often modelled using a log link function (Gilleland and Katz, 2016)

$\ln \sigma(t)=\sigma_{1} t+\sigma_{0} \Rightarrow \sigma(t)=\exp \left(\sigma_{1} t+\sigma_{0}\right)$

where $t$ is the time (in years), and $\lambda=\left\{\mu_{1}, \mu_{0}, \sigma_{1}, \sigma_{0}, \zeta\right\}$ are the parameters.

Then we estimate parameters of the nonstationary GEV distribution by integrating BI combined with DE-MC simulation. For AMP intensity, we derive the time-variant parameter(s) from the 50th (the median or the mid-point of the distribution) percentile(s) of the DE-MC sampled parameter(s). We obtain the associated $95 \%$ credible intervals (the bounds) from the 2.5th and 97.5th percentiles of the simulated posterior samples (see Sect. S3 for details). We perform the calculations following Cheng and AghaKouchak (2014) using a MATLAB-based software package, Nonstationary Extreme Value Analysis (NEVA, version 2.0). The Bayes factor followed by the Akaike information criterion (AIC) with a small sample correction $\left(\mathrm{AIC}_{\mathrm{c}}\right)$ are used to identify the best model. $\mathrm{AIC}_{\mathrm{c}}$ claims to avoid overfitting the data as compared to the traditional AIC (Burnham and Anderson, 2004; Hurvich and Tsai, 1995). Here we assess model fitness based on a least square sense of AIC statistics considering the maximum deviation between empirical (obtained from the rank-based plotting position formula) and modelled cumulative distributions (CDF; Dawson et al., 2007; Hu, 2007; Karmakar and Simonovic, 2007). For calculation of $\mathrm{AIC}_{\mathrm{c}}$ statistics, we consider the median of the DE-MC sampled parameters, which can be considered an average or expected value of risk in the historical observation. Besides this, we also assess the performance of models using probability-probability (PP) plots. The derived model parameters are then utilized to obtain DSI using the concept of a $T$-year return period. We discuss the methods to estimate DSI and $T$-year return periods using stationary and nonstationary methods in detail in Sect. S4. To test (statistically) significant differences in the estimated DSI from the best-selected stationary vs. nonstationary models, we calculate standardized $z$ statistics for selected return periods (Madsen et al., 2009; Mikkelsen et al., 2005). We applied the two-sided option with $10 \%$ significance levels to assess the statistical significance of the test statistics (see Sect. S5 for details). Finally, we compared the DSI obtained from nonstationary and stationary models with existing ECgenerated DSI estimates.

\section{Results}

The extreme rainfall statistics show high standard deviation with positive skew behaviour. The skewness is a measure of the asymmetry in the AMP distribution. Positive values of skewness indicate that data are skewed to the right. The skewness of sub-hourly precipitation extremes varies between 0.22 and 4.45, with highest being 30 min AMP record at Hamilton and least being at Oshawa respectively. Likewise, for hourly extremes, the skewness ranges between 0.54 and 2.54, with least being $1 \mathrm{~h}$ AMP at Oshawa and highest is $1 \mathrm{~h}$ AMP at Hamilton respectively. The majority of stations show positive excess kurtosis, which indicates the data have a distinct peak near the mean, which decline rapidly, and have heavy tails. We find the presence of statistically significant autocorrelations in the AMP time series of Toronto International Airport, Hamilton Airport, and Fergus Shand Dam (Sect. S2). We apply nonparametric TPFW to precipitation extremes with a significant autocorrelation (Tables S4.1, S5.1 and S12). However, two successive TPFWs fail to correct the effect of autocorrelation in 12 and $24 \mathrm{~h}$ duration extremes in Shand Dam. Hence we exclude those two time series from frequency analysis (Table S12). The ADF test for nonstationarity is statistically significant in all durations, as indicated by the higher $p$ values. As a complement to the ADF test, we also employed KPSS and PSR tests (Fig. 2; Sect. S2) to check significant nonstationarity. Figure 3 shows the spatial distribution of trends, change points and nonstationarity in short-duration rainfall extremes. We find co-occurrences of trends, change points and nonstationarities in extremes at multiple locations. In general, the three sites in the extreme northeast, the Oshawa WPCP, Trenton Airport, and Kingston P. Station show evidence of statistically significant upshifts and nonstationarities in the time series, whereas the rest of the sites in the southwest exhibit downshifts and statistically significant nonstationarities (Fig. 3). For $2 \mathrm{~h}$ and beyond durations, London International Airport shows the presence of statistically significant downward trends with change 
points. An increase (decrease) in mean precipitation implies an increase (decrease) in heavy precipitation and vice versa. Further, it could also alter the shape of the right-hand tail, changing overall asymmetry in the distribution (Fig. S1), and hence affecting the nature of extremes (Stocker et al., 2013). Furthermore, the presence of opposite signs of trends within a proximity of sites are prominent in all durations, for example, except for $1 \mathrm{~h}$ duration, extremes in all durations at Toronto International Airport and Oshawa WPCP show downwards and upward shifts respectively. Our findings confirm the other study (Burn and Taleghani, 2013), where authors report a lack of spatial structures and presence of different trends within a close vicinity of stations. Further, we find statistically significant monotonic increase and abrupt step changes, both in mean and variance in Oshawa and Trenton respectively (Tables S6 and S10), whereas London shows a (significant) decrease (Table S9) from $6 \mathrm{~h} \mathrm{du}$ ration and beyond. A few sites, such as Windsor, Kingston, and Stratford show (significant) step changes as confirmed by Mann-Whitney and Mood tests (Tables S7, S8, and S11) respectively. On the other hand, Toronto, Hamilton, and Fergus Shand Dam (Tables S4, 4.1, S5, 5.1, and S12) do not exhibit any significant gradual or abrupt changes in the AMP time series. The ADF tests show the presence of nonstationarity in all durations across the sites. To further validate the results of the ADF test, KPSS and PSR tests are employed. The KPSS test detects the presence of nonstationarity at three out of nine sites for $24 \mathrm{~h}$ rainfall extreme at the $5 \%$ significance level, whereas the results of the PSR test indicate nonstationarity across five sites in $24 \mathrm{~h}$ rainfall extremes. While the KPSS test alone could not detect the presence of nonstationarity in any of the extreme series in Oshawa and Stratford respectively, the results of the PSR test could not discern nonstationarity in any of the short-duration rainfall extremes in Windsor. Both of these tests taken together detect the presence of nonstationarity in rainfall extremes across six out of nine sites. We find that even if trends in individual sites may not seem significant, the magnitude of trends (as measured by slope per decade, Tables S4-S12 in Sect. S2) is never zero in any of the sites. Although we present a range of statistical tests to investigate plausible shifts in the time series, we do acknowledge that statistical inferences may be affected by the problem of multiple comparisons resulting in a set of false positive outcomes. On analysing the FDR-based multiple comparison procedure, we find that except Windsor, in all sites the presence of trend and nonstationarities in the time series turns out to be significant with the highest number of statistical tests showing adjusted $p$ value $<0.10$ in Trenton followed by Hamilton. This indicates our analysis is not affected by the issue of multiple comparisons.

A weak trend can also have a significant impact on the results of probability analysis (Porporato and Ridolfi, 1998). Hence even if precipitation extremes often exhibit statistically insignificant trends in a few durations, we assess the performance of both nonstationary and stationary models in all sites. Tables 2-5 list performances of nonstationary vs. stationary models for selected airport locations, whereas Tables S13-S17 present results of the distribution fit for the remaining stations. Barring a few exceptions, the shape parameters in most of the models range between -0.30 and +0.3 , which is an acceptable range of GEV shape parameters, as shown in an earlier study (Martins and Stedinger, 2000). Our results corroborate well with recent research (Papalexiou et al., 2013; Wilson and Toumi, 2005), which showed that a distribution with fat tails (with a GEV shape parameter, $\zeta<0$ ) fits better for the precipitation extremes. The nonstationary models are selected by employing a Bayes factor and a minimum $\mathrm{AIC}_{\mathrm{c}}$ criterion. For example, for the $6 \mathrm{~h}$ duration storm at Hamilton Airport, the nonstationary $\mathrm{GEV}_{t}$-I (nonstationary model with time-varying GEV location) model performed best, as shown by both test metrics. However, in certain cases, nonstationary models do not pass a Bayes-factor test. In such cases, we select the best nonstationary model (i.e. between $\mathrm{GEV}_{t}-\mathrm{I}$ and $\mathrm{GEV}_{t}$-II) following $\mathrm{AIC}_{\mathrm{c}}$ test statistics. Overall values of the Bayes factor indicate that there is no strong evidence to favour or reject any of the three models. In general, although we find the stationary model cannot be rejected, it does not imply that there is no change. We may be unable to detect the apparent signal of nonstationarity due to the strong natural variability present in the data. However, it should be noted that the objective of the present analysis is to compare the design storm obtained from the stationary vs. the best nonstationary model, and not to analyse the best distribution between them.

As a measure of uncertainty, we also report the $95 \%$ credible interval of design rainfall quantiles at a 100 -year return period as a ratio between the upper and lower bounds, which ranges between factors of 1.2-to-1 and 3.9-to-1 in all cases. The performance of time-varying GEV models (Fig. S9) closely follows the spatial pattern as indicated in the trend map (Fig. 3). For example, Trenton Airport, which showed significant upward trends with change points and nonstationarity, is better modelled by the nonstationary GEV distributions for most of the durations. Likewise, we find that in a few cases, $\mathrm{GEV}_{t}$-II fits best if the time series exhibit (significant) evidence of nonstationarity as detected by PSR-test statistics, for example, $15 \mathrm{~min}$ and $12 \mathrm{~h}$ extremes in London and Toronto International Airport (Tables 2 and 5) respectively. However, in many cases, the performances of nonstationary models are often comparable and even superseded by their stationary counterparts (Sect. S3). In fact, the scatter of data points in the PP plots (Figs. S10-S12) suggests a close resemblance between stationary and nonstationary models across all durations. Figure 4 shows the relation between DSI and durations (ranges between $15 \mathrm{~min}$ and $24 \mathrm{~h}$ ) for 100-year return periods estimated by stationary vs. nonstationary GEV distributions. The interquartile range of the boxplot shows the uncertainty in estimated rainfall quantiles obtained using BI. However, the spread of the boxes simulated by the nonstationary model is found to be relatively narrower as com- 
Table 2. Performance of stationary and nonstationary models for Toronto Pearson International Airport.

\begin{tabular}{|c|c|c|c|c|c|c|c|c|c|}
\hline $\begin{array}{l}\text { Time } \\
\text { slice }\end{array}$ & Model & $\begin{array}{l}\text { Location } \\
\text { parameter }\end{array}$ & Scale parameter & $\begin{array}{r}\text { Shape } \\
\text { parameter }\end{array}$ & $\mathrm{AIC}_{\mathrm{c}}$ & $\begin{array}{l}\text { Bayes } \\
\text { factor }\end{array}$ & $\begin{array}{r}\text { LB } \\
(100 \mathrm{yr})\end{array}$ & $\begin{array}{r}\text { UB } \\
(100 \mathrm{yr})\end{array}$ & $\mathrm{UB} / \mathrm{LB}$ \\
\hline \multirow[t]{3}{*}{$15 \mathrm{~min}$} & $\mathrm{GEV}_{t}-0$ & 37.02 & 19.83 & -0.073 & -465.05 & - & 78.85 & 209.56 & 2.66 \\
\hline & $\mathrm{GEV}_{t}-\mathrm{I}$ & $30.11+0.194 t$ & 20.86 & -0.079 & -450.28 & 4.98 & 105.3 & 229.77 & 2.18 \\
\hline & $\mathrm{GEV}_{t}-\mathrm{II}$ & $34.30+0.056 t$ & $\exp (2.68+0.0069 t)$ & -0.11 & -383.58 & 10.47 & 87.66 & 119.42 & 1.36 \\
\hline \multirow[t]{3}{*}{$30 \mathrm{~min}$} & $\mathrm{GEV}_{t}-0$ & 25.65 & 13.14 & 0.019 & -442.29 & - & 58.8 & 155.85 & 2.65 \\
\hline & $\mathrm{GEV}_{t}-\mathrm{I}$ & $17.32+0.21 t$ & 13.44 & -0.075 & -422.67 & 1.47 & 57.9 & 113.37 & 1.96 \\
\hline & $\mathrm{GEV}_{t}$-II & $12.08+0.35 t$ & $\exp (2.77+0.0023 t)$ & -0.20 & -351.22 & 74357.2 & 58.63 & 99 & 1.69 \\
\hline \multirow[t]{3}{*}{$1 \mathrm{~h}$} & $\mathrm{GEV}_{t}-0$ & 19.77 & 7.79 & 0.07 & -477.68 & - & 45.47 & 101.33 & 2.22 \\
\hline & $\mathrm{GEV}_{t}-\mathrm{I}$ & $18.27+0.022 t$ & 8.59 & -0.08 & -402.43 & 78.53 & 42.27 & 63.57 & 1.50 \\
\hline & $\mathrm{GEV}_{t}-\mathrm{II}$ & $4.44+0.414 t$ & $\exp (1.71+0.015 t)$ & 0.044 & -372.2 & $4.43 \times 10^{9}$ & 49.65 & 87.11 & 1.75 \\
\hline \multirow[t]{3}{*}{$2 \mathrm{~h}$} & $\mathrm{GEV}_{t}-0$ & 11.79 & 4.45 & 0.11 & -477.64 & - & 28.24 & 58.52 & 2.07 \\
\hline & $\mathrm{GEV}_{t}-\mathrm{I}$ & $11.0+0.02 t$ & 4.74 & -0.02 & -449.02 & 13.95 & 27.24 & 40.98 & 1.50 \\
\hline & $\mathrm{GEV}_{t}-\mathrm{II}$ & $11.46-0.0053 t$ & $\exp (1.52-0.00072 t)$ & 0.28 & -421.44 & 9.08 & 46.44 & 61.47 & 1.32 \\
\hline \multirow[t]{3}{*}{$6 \mathrm{~h}$} & $\mathrm{GEV}_{t}-0$ & 4.98 & 1.50 & 0.26 & -488.39 & - & 13.71 & 21 & 1.53 \\
\hline & $\mathrm{GEV}_{t}-\mathrm{I}$ & $5.12+0.0005 t$ & 1.57 & 0.24 & -496.92 & 0.15 & 12.02 & 29.77 & 2.48 \\
\hline & $\mathrm{GEV}_{t}$-II & $5.44-0.0049 t$ & $\exp (0.77-0.0042 t)$ & 0.10 & -424.07 & 52.13 & 13.71 & 21.0 & 1.53 \\
\hline \multirow[t]{3}{*}{$12 \mathrm{~h}$} & $\mathrm{GEV}_{t}-0$ & 2.96 & 0.70 & 0.36 & -503.23 & - & 6.59 & 25.72 & 3.90 \\
\hline & $\mathrm{GEV}_{t}-\mathrm{I}$ & $3.02-0.0031 t$ & 0.69 & 0.51 & -501.42 & 1.39 & 12.4 & 21.98 & 1.77 \\
\hline & $\mathrm{GEV}_{t}-\mathrm{II}$ & $3.13-0.0045 t$ & $\exp (-0.183-0.0032 t)$ & 0.49 & -511.69 & 0.86 & 12.89 & 20.58 & 1.60 \\
\hline \multirow[t]{3}{*}{$24 \mathrm{~h}$} & $\mathrm{GEV}_{t}-0$ & 1.71 & 0.41 & 0.29 & -477.04 & - & 3.69 & 11.71 & 3.17 \\
\hline & $\mathrm{GEV}_{t}-\mathrm{I}$ & $1.73-0.0006 t$ & 0.41 & 0.28 & -466.25 & 13.22 & 3.75 & 10.41 & 2.78 \\
\hline & $\mathrm{GEV}_{t}-\mathrm{II}$ & $1.66+0.00093 t$ & $\exp (-1.00+0.00274 t)$ & 0.30 & -460.06 & 1.30 & 4.28 & 8.16 & 1.91 \\
\hline
\end{tabular}

* $\mathrm{GEV}_{t}-0$ is a stationary model, whereas $\mathrm{GEV}_{t}$-I and $\mathrm{GEV}_{t}$-II are nonstationary models with a time-variant mean, and both a time-variant mean and standard deviation respectively. The selected best fitted nonstationary model is marked in bold letters. The Bayes factor, $\gamma<1$, indicates that the nonstationary model fits better than the stationary model. However, in cases where $\gamma>1$, to compare with the stationary model, the nonstationary model is selected following minimum AIC $\mathrm{C}_{\mathrm{c}}$ criteria. LB and UB indicate the lower and upper bounds of DSI at a 100-year return period

pared to the one simulated by the stationary model for most of the sites (Fig. 4), indicating less uncertainty in the estimated quantiles. For shorter return periods, such as 10 and 5 years, the DSI from stationary vs. nonstationary models shows more or less subtle differences (Figs. S13-S14) than those for the 100-year period.

Figure 5 displays the differences in DSI obtained using the best performing nonstationary model relative to the stationary models using percentage changes and $z$ statistics for different durations and return periods. While percentage change indicates a magnitude of change, the $z$ statistics show the statistical significance of the relative difference in estimated DSI using the two different methods. The percentage differences at the 2- and 10-year return periods are small relative to longer return periods. At the 100-year return period, a maximum positive difference of around $44 \%$ is observed at the $12 \mathrm{~h}$ storm duration in Toronto International Airport (Table S18.1). The standardized $z$ statistics show positive (negative) values, indicating an increase (decrease) in DSI values assuming nonstationarity in return period estimates against their stationary counterparts. However, a comparison between $T$-year event estimates from both models indicates statistically indistinguishable differences in rainfall intensity. We find that, for all return periods and dura- tions, $z$ statistics range between -1 and +1 across all nine sites (Sect. S5). Nonetheless, extreme precipitation intensity shows either positive or negative (statistically insignificant) changes in signs. The difference between DSI shows a decrease, at 1 and $2 \mathrm{~h}$ storm duration in Toronto, $6 \mathrm{~h}$ storm duration in London, and $15 \mathrm{~min}$ and $12 \mathrm{~h}$ storm duration at Trenton Airport for 50- and 100-year return periods (Fig. 5; Sect. S5). In contrast, Toronto, Windsor, and London International Airport show an increase in DSI values at $15 \mathrm{~min}$ duration (Fig. 5; Sect. S5), although the increase is statistically insignificant. Further, we note that, except for the 6 and $12 \mathrm{~h}$ storm durations, the performance statistics show a comparable and in a few cases even better performance of the stationary vs. nonstationary GEV models across most of the sites (Sect. S3). At 2- and 10-year return periods, which are typical for most urban drainage planning, the differences are close to zero (Fig. 5, Tables S27 and S28 in Sect. S5) for most of the duration.

Figures 6 and 7 compare the $T$-year event estimates of updated vs. EC-generated IDFs for different return periods, taking into account both stationary and nonstationary conditions. The median and associated lower and upper bounds of the ratio of regional updated vs. EC-generated $T$-year event estimates can be interpreted as analogous to the most likely 
Table 3. Performance of stationary and nonstationary models for Hamilton Airport.

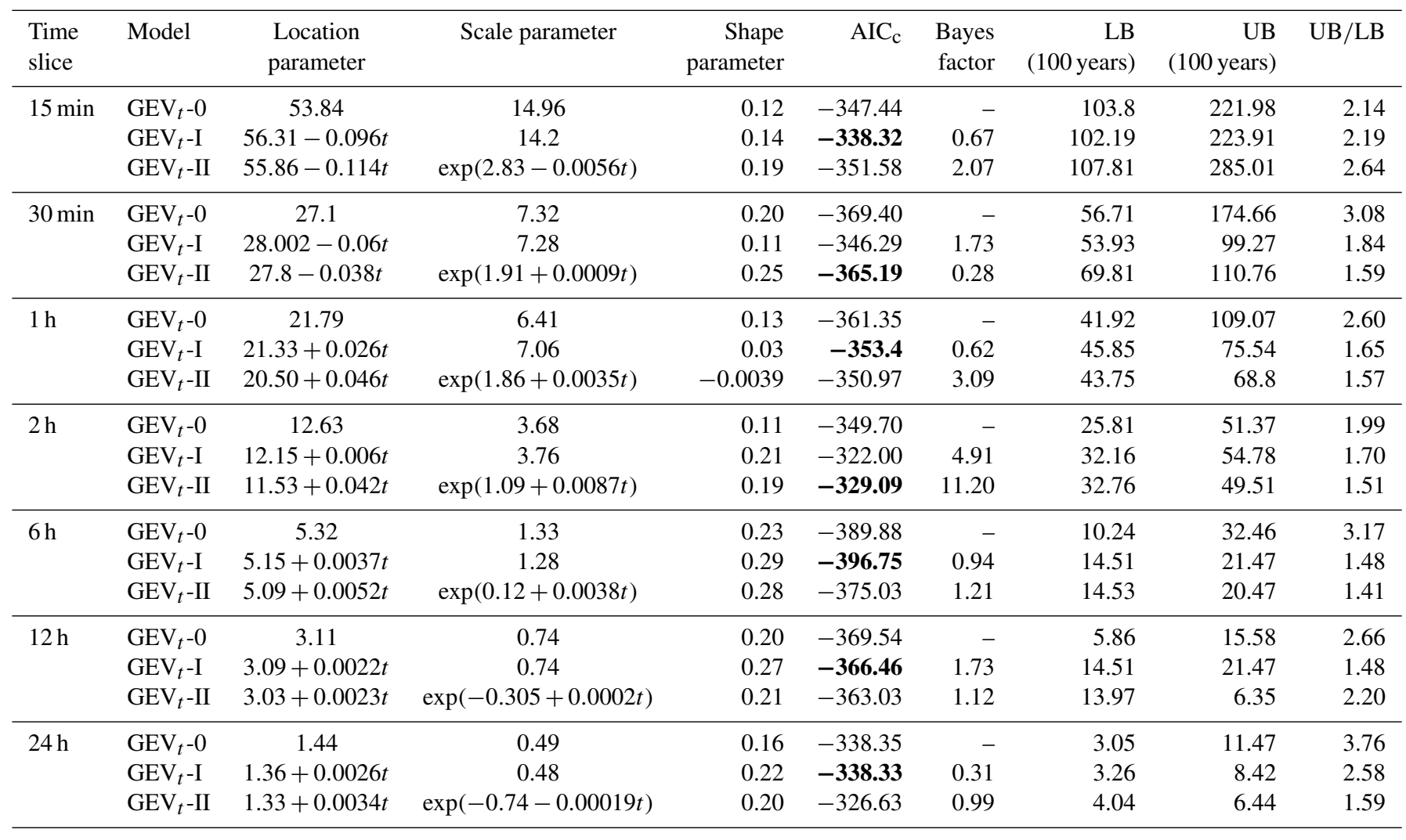

* $\mathrm{GEV}_{t}-0$ is a stationary model, whereas $\mathrm{GEV}_{t}-\mathrm{I}$ and $\mathrm{GEV}_{t}$-II are nonstationary models with a time-variant mean, and both a time-variant mean and standard deviation respectively.

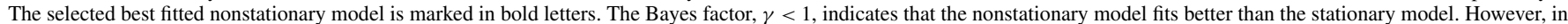
cases where $\gamma>1$, to compare with the stationary model, the nonstationary model is selected following minimum AIC $\mathrm{C}_{\mathrm{c}}$ criteria. LB and UB indicate the lower and upper bounds of DSI at a 100-year return period.

minimum and maximum plausible scenarios. While the positive value of the ratio indicates a required increase in DSI, the negative value indicates a decrease in the DSI estimate. Considering nonstationarity, at the $T=10$-year return period (Fig. 6; Sect. S4), the ratio of updated vs. old estimates of DSI is of the order of $\sim 1.01-1.08$, which indicates that the required increases are of the order of 1.4 to $7.2 \%$. At the $T=2$-year return period, except for Oshawa and Windsor, the majority of sites show a decrease in DSI for most of the storm durations (Fig. 6, middle row). In contrast, an increase in the estimated ratio is more pronounced at the 50- and 100 -year return periods, which are of the order of $\sim 1.03$ 1.80 (Fig. 7, Sect. S4). While for Toronto International Airport and Hamilton Airport, we find no increase in the shortduration rainfall extremes of less than $1 \mathrm{~h}$ and the 50-year return period considering the nonstationary condition, the increase is more pronounced for longer durations and return periods $(12$ and $24 \mathrm{~h}$, and the 50- and 100-year return periods; Sect. S4). For longer recurrence intervals, while the heat maps of minimum bounds and the most likely scenario show a smaller number of stations and durations to reach a ratio of 1.5 and beyond, the maximum bounds suggest a sharp increase in the ratio across all durations and locations. Further, for return periods of 50 years and more, the increase in the ratio is more prominent in the upper bound of the stationary models (Fig. 7, left two columns) as compared to the nonstationary models. The resulting increase in $T$-year event estimates is because of the relatively wider confidence interval of estimated DSIs in stationary models than that of the nonstationary models (Fig. 4; Sect. S3). In general, for longer return periods, our analysis reveals that the increase in the ratio of updated vs. EC-generated rainfall intensity is more prominent in sites with statistically significant signatures of nonstationarity, upward trends, and change points. For example, the updated DSIs of Oshawa WPCP, Windsor, and Trenton Airport shows an increase in the ratio for most of the durations and return periods as compared to the EC-generated DSI values (Sect. S4). On the other hand, except for the 100-year return period events, the hourly precipitation extremes in London International Airport, in general, show a decrease in the ratio (Tables S23.1-23.2) across all return periods, which is predominantly due to the presence of significant downward trends with change points in the time series.

Based on the study results and in anticipation of stakeholders' participation in adaptive management, we present updated IDFs for four selected urbanized locations across 
Table 4. Performance of stationary and nonstationary models for Windsor Airport.

\begin{tabular}{|c|c|c|c|c|c|c|c|c|c|}
\hline $\begin{array}{l}\text { Time } \\
\text { slice }\end{array}$ & Model & $\begin{array}{l}\text { Location } \\
\text { parameter }\end{array}$ & Scale parameter & $\begin{array}{r}\text { Shape } \\
\text { parameter }\end{array}$ & $\mathrm{AIC}_{\mathrm{c}}$ & $\begin{array}{l}\text { Bayes } \\
\text { factor }\end{array}$ & $\begin{array}{r}\text { LB } \\
\text { (100 years) }\end{array}$ & $\begin{array}{r}\text { UB } \\
\text { (100 years) }\end{array}$ & $\mathrm{UB} / \mathrm{LB}$ \\
\hline \multirow[t]{3}{*}{$15 \mathrm{~min}$} & $\mathrm{GEV}_{t}-0$ & 60.04 & 15.76 & 0.13 & -394.2 & - & 106.43 & 300.24 & 2.82 \\
\hline & $\mathrm{GEV}_{t}-\mathrm{I}$ & $61.6-0.099 t$ & 14.61 & 0.25 & -370.00 & 0.80 & 157.9 & 227.06 & 1.44 \\
\hline & $\mathrm{GEV}_{t}-\mathrm{II}$ & $63.33-0.068 t$ & $\exp (2.67+0.0027 t)$ & 0.013 & -376.75 & 5.36 & 115.47 & 166.94 & 1.44 \\
\hline \multirow[t]{3}{*}{$30 \mathrm{~min}$} & $\mathrm{GEV}_{t}-0$ & 38.92 & 12.94 & 0.06 & -443.89 & - & 72.9 & 179.38 & 2.46 \\
\hline & $\mathrm{GEV}_{t}-\mathrm{I}$ & $43.20-0.124 t$ & 12.04 & 0.12 & -435.12 & 0.25 & 72.6 & 210.06 & 2.89 \\
\hline & $\mathrm{GEV}_{t}$-II & $42.81-0.11 t$ & $\exp (2.33+0.0032 t)$ & -0.0096 & -371.83 & 1.002 & 81.7 & 104.43 & 1.28 \\
\hline \multirow[t]{3}{*}{$1 \mathrm{~h}$} & $\mathrm{GEV}_{t}-0$ & 24.82 & 8.00 & 0.044 & -459.27 & - & 46.8 & 112.2 & 2.40 \\
\hline & $\mathrm{GEV}_{t}-\mathrm{I}$ & $28.93-0.14 t$ & 7.1 & 0.14 & -452.65 & 0.35 & 58.99 & 89.75 & 1.52 \\
\hline & $\mathrm{GEV}_{t}$-II & $28.86-0.12 t$ & $\exp (2.11-0.0005 t)$ & 0.024 & -444.90 & 0.22 & 56.66 & 73.64 & 1.30 \\
\hline \multirow[t]{3}{*}{$2 \mathrm{~h}$} & $\mathrm{GEV}_{t}-0$ & 15.79 & 5.12 & -0.14 & -476.71 & - & 25.62 & 45.09 & 1.76 \\
\hline & $\mathrm{GEV}_{t}-\mathrm{I}$ & $17.58-0.073 t$ & 4.78 & -0.02 & -434.62 & 0.38 & 26.13 & 58.27 & 2.23 \\
\hline & $\mathrm{GEV}_{t}-\mathrm{II}$ & $17.70-0.07 t$ & $\exp (1.50+0.0049 t)$ & -0.14 & -475.53 & 0.16 & 29.79 & 37.83 & 1.27 \\
\hline \multirow[t]{3}{*}{$6 \mathrm{~h}$} & $\mathrm{GEV}_{t}-0$ & 6.24 & 1.86 & 0.041 & -472.16 & - & 11.85 & 23.23 & 1.96 \\
\hline & $\mathrm{GEV}_{t}-\mathrm{I}$ & $6.80-0.014 t$ & 1.94 & -0.04 & -477.91 & 0.52 & 12.45 & 16.77 & 1.35 \\
\hline & $\mathrm{GEV}_{t}$-II & $6.85-0.017 t$ & $\exp (0.64+0.0013 t)$ & 0.040 & -480.19 & 0.65 & 14.28 & 18.75 & 1.31 \\
\hline \multirow[t]{3}{*}{$12 \mathrm{~h}$} & $\mathrm{GEV}_{t}-0$ & 3.47 & 0.98 & 0.10 & -489.97 & - & 6.3 & 16.67 & 2.65 \\
\hline & $\mathrm{GEV}_{t}-\mathrm{I}$ & $3.97-0.016 t$ & 0.92 & 0.14 & -461.74 & 0.20 & 6.75 & 14.51 & 2.15 \\
\hline & $\mathrm{GEV}_{t}-\mathrm{II}$ & $3.89-0.012 t$ & $\exp (-0.055+0.00094 t)$ & 0.09 & -481.94 & 0.20 & 7.7 & 10.57 & 1.37 \\
\hline \multirow[t]{3}{*}{$24 \mathrm{~h}$} & $\mathrm{GEV}_{t}-0$ & 2.04 & 0.53 & 0.03 & -475.90 & - & 3.42 & 7.36 & 2.15 \\
\hline & $\mathrm{GEV}_{t}-\mathrm{I}$ & $2.05-0.011 t$ & 0.53 & 0.03 & -472.08 & 2.44 & 3.41 & 7.15 & 2.09 \\
\hline & $\mathrm{GEV}_{t}-\mathrm{II}$ & $1.74+0.0067 t$ & $\exp (-0.78+0.0054 t)$ & 0.0056 & -415.7 & 30.74 & 3.66 & 5.84 & 1.60 \\
\hline
\end{tabular}

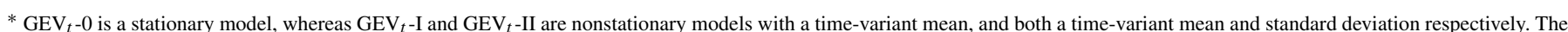

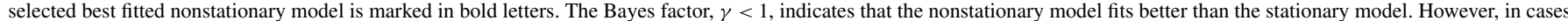

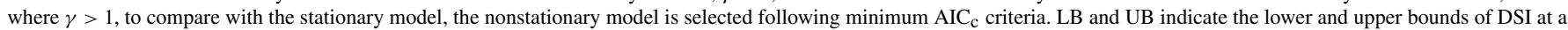
100 -year return period.

Southern Ontario (Fig. 8). In order to distinguish between stationary and nonstationary methods of analysis, we also present updated IDF assuming stationary condition relative to EC IDF in the same plot (in the top panel). The comparison of remaining sites is presented in Fig. S15. Thus we made the first attempt to compare the results of updated vs. EC-generated IDFs considering both nonstationary and stationary conditions, which are the part of contemporary design standards and widely used by the stakeholders and practitioners. Overall, the updated IDFs closely follow the pattern of trends analogous to EC-generated IDFs, except for the 100-year return period. The difference is more pronounced considering nonstationary condition, especially at Toronto International Airport (Fig. 8), Oshawa WPCP, and Stratford WWTP (Fig. S15). At longer durations and return periods, stations in metropolitan areas (such as Toronto International Airport, Hamilton Airport, Oshawa WPCP, and Windsor Airport) show large differences in DSIs, whereas moderately populated locations such as Kingston P. Station and Fergus Shand Dam show a relatively small change. Considering the nonstationary condition, the maximum increase at Fergus Shand Dam is noted as $18.7 \%$ for the $2 \mathrm{~h}$ storm duration and 100-year return period, whereas an increase of around $44.5 \%$ is shown for the $12 \mathrm{~h}$ storm duration at Toronto International Airport. For $T=10$ years or less, we find a decrease in the range of $\sim 2-40 \%$ in the $T$-year event estimates (Sect. S4). Meanwhile, for the $T=10$-year return period, we find that the increase is of the order of $\sim 1.4$ to $7.2 \%$ across several stations. Considering nonstationarity, at $T=50$ years and more, the required increase ranges between $\sim 2.8$ and $44.5 \%$. We find that the largest increase is for the $12 \mathrm{~h}$ rainfall extreme in Toronto International Airport $(\sim 32$ $44.5 \%$; Table S18.1), followed by a $2 \mathrm{~h}$ extreme at Stratford WWTP ( 27-36\%; Table S25.1). However, considering the stationarity condition at $T=50$ years and more, the required increase ranges between $\sim 1.4$ and $26 \%$. It should be noted that above results are based on an average risk approach for extreme value analysis considering median of the sampled parameters in the historical observation and not taking into account the overall risk envelope (i.e. minimum and maximum bounds). In summary, our findings confirm that updates of the order of $\sim 2-44 \%$ are required based on locations and return periods to mitigate the risk of precipitation-induced urban flooding irrespective of the choice of methods used in the IDF estimation (Sect. S4). The results are consistent with Simonovic and Peck (2009), in which the authors rec- 
Table 5. Performance of stationary and nonstationary models for London International Airport.

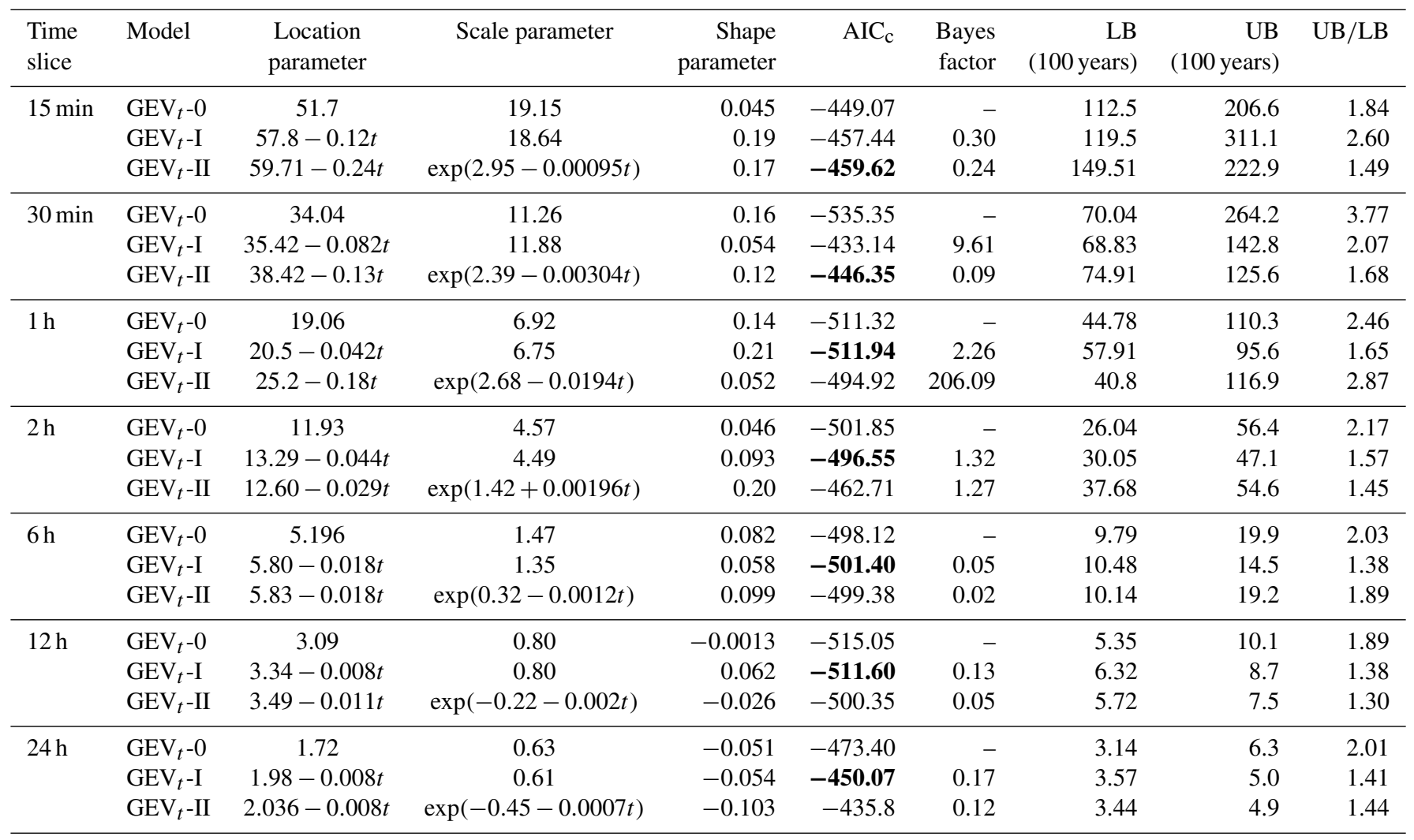

* $\mathrm{GEV}_{t}-0$ is a stationary model, whereas $\mathrm{GEV}_{t}$-I and $\mathrm{GEV}_{t}$-II are nonstationary models with a time-variant mean, and both a time-variant mean and standard deviation respectively.

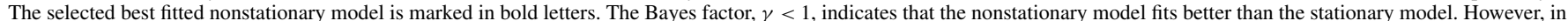
cases where $\gamma>1$, to compare with the stationary model, the nonstationary model is selected following minimum AIC $\mathrm{C}_{\mathrm{c}}$ criteria. LB and UB indicate the lower and upper bounds of DSI at the 100-year return period.

ommend an average update of about $21 \%$, with a difference, range between $\sim 11$ and $35 \%$ for the updated vs. EC-IDF in the London metropolitan area. However, they assumed stationarity condition to develop at-site IDF. The above results also highlight the need to update existing EC IDFs, which are generated using Gumbel probability distributions and do not fit the data well.

\section{Discussions and conclusions}

This paper has sought to assess signatures of nonstationarity in densely and moderately populated urbanized locations across Southern Ontario, which is one of the major economic hubs in Canada. We update short-duration rainfall extremes with latest available ground-based observations and present a comprehensive analysis to evaluate nonstationary vs. the stationary method of IDF estimation. This analysis yields two principal findings. First, detectable nonstationarity in rainfall extremes does not necessarily lead to significant differences in design storm values. Second, comparison of at-site $T$-year event estimates of updated vs. ECgenerated IDFs shows at $T=10$ years, the return period commonly used for urban drainage design, current design standards require updates of up to $7 \%$ to mitigate the risk of urban flooding. Meanwhile, for a longer recurrence interval ( $T=50$ years or more), typical for critical civil infrastructural design, comparison of updated vs. EC-generated IDF curves shows a difference ranges between 2 and $44 \%$ based on locations. These findings pose an important question: does the presence of nonstationarities in rainfall extremes require the design of nonstationary IDF curves? We argue that although it is crucial to recognize nonstationarity in precipitation extremes, the stationary form of IDFs can still represent the extreme rainfall statistics for the present-day climate over the Southern Ontario region. Our results are consistent with Yilmaz et al. (2014) and Yilmaz and Perera (2013), in which authors found despite the presence of (statistically) significant trends in rainfall extremes; nonstationary GEV models did not show any additional advantages over the stationary models. As supported by the previous study (Singh et al., 2016), we attribute that the little or no changes in extreme rainfall statistics in the urbanized setting is due to the stabilization of urban development leading to no substantial variations in the land use pattern. Hence, no significant changes in 
synoptic-scale circulations, which in turn affect space-time pattern in rainfall extremes (Moglen and Schwartz, 2006).

Preliminary investigations based on regional and global climate model simulations in the study area confirm a considerable uncertainty in the projection of short-duration and high-intensity extreme rain events (Coulibaly et al., 2015). While short-duration precipitation extremes are typically controlled by synoptic-scale moisture convergence (RuizVillanueva et al., 2012; Westra and Sisson, 2011), the daily extremes are often modulated by large-scale circulation patterns and local orographic factors (Carvalho et al., 2002; Gershunov and Barnett, 1998; Trenberth, 1999). The roles of natural variability and multidecadal modes of sea-surface temperature (SST) in modulating Canadian extreme rainfall intensity have already been shown in the past (Gan et al., 2007; Shabbar et al., 1997). Further, a review of the literature suggests that heavy precipitation does not necessarily lead to high stream discharge (Ivancic and Shaw, 2015; Do et al., 2017; Wasko and Sharma, 2017). The analysis of Do et al. (2017) reveals that the trend in streamflow is more consistent across the continental scale, and neither the anthropogenic activities such as the presence of dams nor the vegetation cover have any significant effect on the results of trend estimates. Interestingly, the consensus among all three studies (Ivancic and Shaw, 2015; Do et al., 2017; Wasko and Sharma, 2017) is that the catchment size, which regulates the flow response because of the antecedent moisture content, is the most important contributing factor in modulating the nature of a trend in stream discharge. The smaller (especially urban) catchments may have increased flood peaks; in contrast, larger (agricultural and rural) catchments may experience decreased runoff due to lower soil moisture. This can be attributed to the fact that high temperature leads to drying up of soil more quickly in larger catchments, thus forcing a large portion of precipitation not to become an overland flow. Finally, using more than 9000 daily streamflow records globally, Do et al. (2017) showed more stations with significant decreasing trends in annual maximum streamflow than that of significant increasing trends, indicating limited evidence of increasing flood hazards. Their findings are corroborated by Wasko and Sharma (2017), in which the authors showed that only in the most extreme cases, for small catchments, does an increase in precipitation at a higher temperature lead to an increase in streamflow.

The statistical uncertainty in modelling nonstationarity can result from multiple sources, for instance, extrapolating the effects detected with observed historical series to the more extreme values that have not yet been experienced, model choices resulting from selection of covariates in the nonstationary distributions (Agilan and Umamahesh, 2017), and the treatment of nonstationarity introduced through either a linear (Ali and Mishra, 2017; Cheng et al., 2014; Westra et al., 2012) or polynomial (Villarini et al., 2009b) trend, or a change point (Renard et al., 2013) in the model. The key question remains how to update design events in a nonsta- tionary climate. This becomes more challenging after trends and change points are detected in hydrometric time series. To address climate change adaptation needs under nonstationarity and uncertainty, some of the concepts discussed in the literature are design life level (Rootzén and Katz, 2013) to quantify the probability of exceeding a fixed threshold during the design life of a project, replacing the commonly used concept of average return period with reliability (Read and Vogel, 2015) and a risk-based decision-making approach integrating the concept of expected regret (Rosner et al., 2014). However, apart from statistical uncertainty, one of the important sources of uncertainty in future planning periods is the use of climate model output. Modelling nonstationarity in the future time period is complicated by the choice of spatial resolution of climate models, lack of understanding of model physics due to different model choices, and inherent uncertainties in climate model realizations resulting from different initial conditions, which is especially apparent over regional scales and decadal planning horizons (Ganguli et al., 2017; Hawkins and Sutton, 2009; Kumar and Ganguly, 2017; Meehl et al., 2009).

The increase in design storm during the update process could also indicate a tendency towards an increase in mean precipitation and (or) a shift in the distribution, affecting its tail behaviour. However, a few caveats remain: for example, a critical question could be "is an increase in DSI potentially linked to more frequent and more intense precipitation extremes or is it an artifact of the new dataset in the update process?" It is worthwhile noting that the results shown here are manifestations of the present-day climate using groundbased hydrometeorological observations, and the specific insights are nonetheless subject to the quality of available rainfall records. It remains an open-ended question to what extent we can credibly develop IDFs in a changing climate (Coulibaly et al., 2015) since there is no uniformly accepted method of generating IDF information and related projection uncertainty in the light of climate change. Firstly, highlighting advantages and limitations of nonstationary vs. stationary methods of analyses (Koutsoyiannis and Montanari, 2015; Montanari and Koutsoyiannis, 2014; Serinaldi and Kilsby, 2015; Serinaldi et al., 2018) is beyond the scope of the current study. Secondly, one of the limitations of the present analysis includes the lack of accounting for the consistency of the IDF curves in terms of shape enforcement. The lack of shape enforcement in the IDF curves (Figs. 8 and S15) is the result of fitting separate distributions to the series of different durations. Finally, although in several instances we do find evidence of step changes in short-duration rainfall extremes, we have not introduced any change-point model in the GEV parameters (Renard et al., 2013).

Future research should include two aspects. First, investigation of physical drivers (such as temperature, decadal, and multidecadal modes of SST) influencing short-duration rainfall extremes, and inclusion of these covariates in nonstationary IDF development. Second, modelling nonstationarity by 
introducing a step-change model in GEV location and scale parameters. Finally, given that the findings reported herein are for the current period (e.g. historical extreme rainfall time series), we recommend a careful extrapolation of these findings with regards to future climate projections, in which the frequency and magnitude of extreme rainfall are expected to intensify (Mailhot et al., 2012; Deng et al., 2016; Fischer and Knutti, 2016; Prein et al., 2016, 2017; Pfahl et al., 2017; Switzman et al., 2017). Further work should consider nonstationary methods for deriving future IDFs in Southern Ontario.

Data availability. The annual maximum rainfall data used in this study are downloaded from the Environment Canada (EC, 2014), Engineering Climate Datasets archive. The hourly (HLY) and daily (DLY) rainfall data are obtained from Environment and Climate Change Canada (ECCC, 2017). The 2011 census data and census digital boundary shape files are obtained from the Statistics Canada (SC, 2016) website.

\section{The Supplement related to this article is available online at https://doi.org/10.5194/hess-21-6461-2017- supplement.}

Author contributions. PG and PC designed the experiment. PG carried out the experiment. PG prepared the manuscript with contributions from PC.

Acknowledgements. This work was supported by the Natural Science and Engineering Research Council (NSERC) Canadian FloodNet (grant number: NETGP 451456). The first author of the paper would like to thank Jonas Olsson of the Swedish Meteorological and Hydrological Institute (SMHI), Norrköping, Sweden, for sharing MATLAB-based random cascade disaggregation tools and implementation details by email. While change-point and nonstationarity analyses were conducted in statistical software R version 3.30 with add-on packages "trend", "fractal", and "cpm", the remaining analyses were performed in a MATLAB platform (MATLAB R2016a). The nonstationary GEV analyses were performed using the MATLAB-based NEVA toolbox, available at the University of California, Irvine, website: http://amir.eng.uci.edu/neva.php (as accessed on May 2016). The work was completed and communicated when the first author was a postdoctoral research fellow at McMaster Water Resources and Hydrologic Modeling Lab, McMaster University, Canada.

Edited by: Thomas Kjeldsen

Reviewed by: two anonymous referees

\section{References}

Adamowski, K. and Bougadis, J.: Detection of trends in annual extreme rainfall, Hydrol. Process., 17, 3547-3560, 2003.

Agilan, V. and Umamahesh, N. V.: What are the best covariates for developing non-stationary rainfall Intensity-DurationFrequency relationship?, Adv. Water Resour., 101, 11-22, 2017.

Ali, H. and Mishra, V.: Contrasting response of rainfall extremes to increase in surface air and dewpoint temperatures at urban locations in India, Sci. Rep.-UK, 7, 1228, https://doi.org/10.1038/s41598-017-01306-1, 2017.

ASCE: Standard Guidelines for the Design of Urban Stormwater Systems, Standard Guidelines for Installation of Urban Stormwater Systems, and Standard Guidelines for the Operation and Maintenance of Urban Stormwater Systems, ASCE/EWRI 4505, 46-05, and 47-05, American Society of Civil Engineers, Reston, VA, available at: https://ascelibrary.org/doi/book/10.1061/ 9780784408063 (last access: 9 December 2016), 2006.

Baldwin, D. J. B., Desloges, J. R., and Band, L. E.: Physical geography of Ontario, in: Ecology of a Managed Terrestrial Landscape: Patterns and Processes of Forest Landscapes in Ontario, University of British Columbia Press, Vancouver, 2011.

Ban, N., Schmidli, J., and Schär, C.: Evaluation of the convectionresolving regional climate modeling approach in decade-long simulations, J. Geophys. Res.-Atmos., 119, 7889-7907, 2014.

Berg, P., Moseley, C., and Haerter, J. O.: Strong increase in convective precipitation in response to higher temperatures, Nat. Geosci., 6, 181-185, 2013.

Benjamini, Y. and Hochberg, Y.: Controlling the false discovery rate: a practical and powerful approach to multiple testing, J. Roy. Stat. Soc. B Met., 57, 289-300, 1995.

Berkley Earth: Local climate change: $44.20^{\circ} \mathrm{N}, 80.50^{\circ} \mathrm{W}$, available at: http://berkeleyearth.lbl.gov, last access: December 2017.

Blenkinsop, S., Chan, S. C., Kendon, E. J., Roberts, N. M., and Fowler, H. J.: Temperature influences on intense UK hourly precipitation and dependency on large-scale circulation, Environ. Res. Lett., 10, 054021, 2015.

Bougadis, J. and Adamowski, K.: Scaling model of a rainfall intensity-duration-frequency relationship, Hydrol. Process., 20, 3747-3757, 2006.

Bourne, L. S. and Simmons, J.: New fault lines? Recent trends in the Canadian Urban System and their implications for planning and public policy, Can. J. Urban Res., 12, 22-47, 2003.

Burn, D. H. and Taleghani, A.: Estimates of changes in design rainfall values for Canada, Hydrol. Process., 27, 1590-1599, 2013.

Burnham, K. P. and Anderson, D. R.: Multimodel inference understanding AIC and BIC in model selection, Sociol. Methods Res., 33, 261-304, 2004.

Cannon, A. J.: A flexible nonlinear modelling framework for nonstationary generalized extreme value analysis in hydroclimatology, Hydrol. Process., 24, 673-685, https://doi.org/10.1002/hyp.7506, 2010.

Carvalho, L. M., Jones, C., and Liebmann, B.: Extreme precipitation events in southeastern South America and large-scale convective patterns in the South Atlantic convergence zone, J. Climate, 15, 2377-2394, 2002.

Castellarin, A., Kohnová, S., Gaál, L., Fleig, A., Salinas, J. L., Toumazis, A., Kjeldsen, T. R., and Macdonald, N.: Review of applied-statistical methods for flood-frequency analysis in Eu- 
rope, available at: http://nora.nerc.ac.uk/19286/ (last access: 20 May 2017), 2012.

CCF (Canadian Climate Forum): Extreme Weather, 1, 1-4, Ottawa, available at: http://www.climateforum.ca/ (last access: December 2016), 2013.

CDD (Canadian Disaster Database): Public Safety Canada, available at: https://www.publicsafety.gc.ca/cnt/rsrcs/ cndn-dsstr-dtbs/index-en.aspx (last access: December 2016), 2015.

Cheng, L. and AghaKouchak, A.: Nonstationary precipitation intensity-duration-frequency curves for infrastructure design in a changing climate, Sci. Rep.-UK, 4, 7093, https://doi.org/10.1038/srep07093, 2014.

Cheng, C. S., Li, G., Li, Q., and Auld, H.: A synoptic weather typing approach to simulate daily rainfall and extremes in Ontario, Canada: potential for climate change projections, J. Appl. Meteorol. Clim., 49, 845-866, https://doi.org/10.1175/2010JAMC2016.1, 2010.

Cheng, L., AghaKouchak, A., Gilleland, E., and Katz, R. W.: Nonstationary extreme value analysis in a changing climate, Climatic Change, 127, 353-369, 2014.

Chowdhury, A. and Mavrotas, G.: FDI and growth: what causes what?, World Econ., 29, 9-19, 2006.

Coles, S.: An Introduction to Statistical Modeling of Extreme Values, Springer, 1-183, 2001.

Coulibaly, P. and Shi, X.: Identification of the effect of climate change on future design standards of drainage infrastructure in Ontario, Rep. Prep. McMaster Univ. Funding Minist. Transp. Ont., 82, available at: http://www.cspi.ca/sites/default/ files/download/Final_MTO_Report_June2005rv.pdf (last access: 9 December 2016), 2005.

Coulibaly, P., Burn, D., Switzman, H., Henderson, J., and Fausto, E.: A comparison of future IDF curves for Southern Ontario, Technical Report, McMaster University, Hamilton, available at: https://climateconnections.ca/wp-content/uploads/2014/ 01/IDF-Comparison-Report-and-Addendum.pdf (last access: 9 December 2016), 2015.

CSA (Canadian Standards Association): Technical Guide - Development, Interpretation and Use of Rainfall Intensity-durationfrequency (IDF) Information: Guideline for Canadian Water Resources Practitioners, CSA Group, Ottawa, 2010.

Dawson, C. W., Abrahart, R. J., and See, L. M.: HydroTest: A webbased toolbox of evaluation metrics for the standardised assessment of hydrological forecasts, Environ. Modell. Softw., 22, 1034-1052, https://doi.org/10.1016/j.envsoft.2006.06.008, 2007.

Dean, S. M., Rosier, S., Carey-Smith, T., and Stott, P. A.: The role of climate change in the two-day extreme rainfall in Golden Bay, New Zealand, December 2011, B. Am. Meteorol. Soc., 94, S61S63, 2013

De Carolis, L.: The urban heat island effect in Windsor, ON: an assessment of vulnerability and mitigation strategies, City Windsor Ont., 2012, 1-52, available at: https://www.citywindsor.ca/ residents/environment/Environmental-Master-Plan/Documents/ UrbanHeatIslandReport(2012).pdf, last access: December 2016.

Deng, Z., Qiu, X., Liu, J., Madras, N., Wang, X., and Zhu, H.: Trend in frequency of extreme precipitation events over Ontario from ensembles of multiple GCMs, Clim. Dynam., 46, 2909-2921, 2016.
Dickey, D. A. and Fuller, W. A.: Likelihood ratio statistics for autoregressive time series with a unit root, Econom. J. Econom. Soc., 49, 1057-1072, 1981.

Dixon, P. G. and Mote, T. L.: Patterns and causes of Atlanta's urban heat island-initiated precipitation, J. Appl. Meteorol., 42, 12731284, 2003.

Do, H. X., Westra, S., and Leonard, M.: A global-scale investigation of trends in annual maximum streamflow, J. Hydrol., 552, 28-43, 2017.

Donat, M. G., Lowry, A. L., Alexander, L. V., O'Gorman, P. A., and Maher, N.: More extreme precipitation in the world's dry and wet regions, Nat. Clim. Change, 6, 508-513, 2016.

Dritsakis, N.: Tourism as a Long-Run Economic Growth Factor: An Empirical Investigation for Greece Using Causality Analysis, Tour. Econ., 10, 305-316, https://doi.org/10.5367/0000000041895094, 2004.

Drobinski, P., Da Silva, N., Panthou, G., Bastin, S., Muller, C., Ahrens, B., Borga, M., Conte, D., Fosser, G., Giorgi, F., Güttler, I., Kotroni, V., Li, L., Morin, E., Önol, B., Quintana-Segui, P., Romera, R., and Torma, C. Z.: Scaling precipitation extremes with temperature in the Mediterranean: past climate assessment and projection in anthropogenic scenarios, Clim. Dynam., 1-21, https://doi.org/10.1007/s00382-016-3083-x , 2016.

Durrans, S. and Brown, P.: Estimation and internet-based dissemination of extreme rainfall information, Transp. Res. Rec. J. Transp. Res. Board, 1743, 41-48, 2001.

EC (Environment Canada): Documentation on Environment Canada Rainfall Intensity-DurationFrequency (IDF) Tables and Graphs V2.20, Government of Canada, 2012.

EC (Environment Canada): Documentation on Environment Canada Rainfall Intensity-DurationFrequency (IDF) Tables and Graphs V2.30, December, 2014, Government of Canada, available at: http://climate.weather.gc.ca/prods_servs/engineering_e. html (last access: December 2016), 2014.

ECCC (Environment and Climate Change Canada): Technical Documentation - Digital Archive of Canadian Climatological Data, Government of Canada, data available at: ftp://client_climate@ ftp.tor.ec.gc.ca/Pub/Documentation_Technical/Technical_ Documentation.pdf (last access: December 2016) from: https://www.canada.ca/en/environment-climate-change.html, 2017.

El Adlouni, S., Ouarda, T. B. M. J., Zhang, X., Roy, R., and Bobée, B.: Generalized maximum likelihood estimators for the nonstationary generalized extreme value model, Water Resour. Res., 43, W03410, https://doi.org/10.1029/2005WR004545, 2007.

IPCC (Intergovernmental Panel on Climate Change): Managing the Risks of Extreme Events and Disasters to Advance Climate Change Adaptation, A Special Report of Working Groups I and II of the Intergovernmental Panel on Climate Change, edited by: Field, C. B., Barros, V., Stocker, T. F., Qin, D., Dokken D. J., Ebi,K. L., Mastrandrea, M. D., Mach, K. J., Plattner, G.-K., Allen, S. K., Tignor, M., and Midgley, P. M., Cambridge University Press, Cambridge, United Kingdom and New York, NY, USA, 582 pp., available at: https://www.ipcc.ch/pdf/ special-reports/srex/SREX_Full_Report.pdf, 2012.

Fischer, E. M. and Knutti, R.: Observed heavy precipitation increase confirms theory and early models, Nat. Clim. Change, 6, 986991, 2016. 
Gan, T. Y., Gobena, A. K., and Wang, Q.: Precipitation of southwestern Canada: wavelet, scaling, multifractal analysis, and teleconnection to climate anomalies, J. Geophys. Res.-Atmos., 112, D10110, https://doi.org/10.1029/2006JD007157, 2007.

Ganguli, P., Kumar, D., and Ganguly, A. R.: US power production at risk from water stress in a changing climate, Sci. Rep.-UK, 7, 11983, https://doi.org/10.1038/s41598-017-12133-9, 2017.

Gershunov, A. and Barnett, T. P.: ENSO influence on intraseasonal extreme rainfall and temperature frequencies in the contiguous United States: observations and model results, J. Climate, 11, 1575-1586, 1998.

Gilleland, E. and Katz, R. W.: Extremes 2.0: an extreme value analysis package in $\mathrm{R}$, J. Stat. Softw., 72, 1-39, https://doi.org/10.18637/jss.v072.i08, 2016.

Gimeno, R., Manchado, B., and Mìnguez, R.: Stationarity tests for financial time series, Physica A, 269, 72-78, https://doi.org/10.1016/S0378-4371(99)00081-3, 1999.

Gu, X., Zhang, Q., Singh, V. P., Xiao, M., and Cheng, J.: Nonstationarity-based evaluation of flood risk in the Pearl River basin: changing patterns, causes and implications, Hydrolog. Sci. J., 62, 246-258, 2017.

Gudmundsson, L., Bremnes, J. B., Haugen, J. E., and EngenSkaugen, T.: Technical Note: Downscaling RCM precipitation to the station scale using statistical transformations - a comparison of methods, Hydrol. Earth Syst. Sci., 16, 3383-3390, 10.5194/hess-16-3383-2012, 2012.

Güntner, A., Olsson, J., Calver, A., and Gannon, B.: Cascadebased disaggregation of continuous rainfall time series: the influence of climate, Hydrol. Earth Syst. Sci., 5, 145-164, https://doi.org/10.5194/hess-5-145-2001, 2001.

Guo, X., Fu, D., and Wang, J.: Mesoscale convective precipitation system modified by urbanization in Beijing City, Atmos. Res., 82, 112-126, https://doi.org/10.1016/j.atmosres.2005.12.007, 2006.

Hamed, K. H. and Rao, A. R.: A modified Mann-Kendall trend test for autocorrelated data, J. Hydrol., 204, 182-196, 1998.

Hardwick Jones, R., Westra, S., and Sharma, A.: Observed relationships between extreme sub-daily precipitation, surface temperature, and relative humidity, Geophys. Res. Lett., 37, L22805, https://doi.org/10.1029/2010GL045081, 2010.

Hawkins, E. and Sutton, R.: The potential to narrow uncertainty in regional climate predictions, B. Am. Meteorol. Soc., 90, 10951107, 2009.

$\mathrm{Hu}, \mathrm{S}$.: Akaike information criterion, Cent. Res. Sci. Comput., NC State University, Raleigh, NC, available at: http://www4.ncsu. edu/ shu3/Presentation/AIC_2012.pdf (last access: 12 December 2016), 2007.

Hurvich, C. M. and Tsai, C.-L.: Model selection for extended quasilikelihood models in small samples, Biometrics, 51, 1077-1084, 1995.

Ivancic, T. J. and Shaw, S. B.: Examining why trends in very heavy precipitation should not be mistaken for trends in very high river discharge, Climatic Change, 133, 681-693, 2015.

Jakob, D.: Nonstationarity in extremes and engineering design, in: Extremes in a Changing Climate, Springer, 363-417, 2013.

Jarvis, A., Reuter, H. I., Nelson, A., and Guevara, E.: Hole-filled SRTM for the globe Version 4, available at: http://www.cgiar-csi. org/data/srtm-90m-digital-elevation-database-v4-1 (last access: 13 December 2016), 2008.
Jebari, S., Berndtsson, R., Olsson, J., and Bahri, A.: Soil erosion estimation based on rainfall disaggregation, J. Hydrol., 436, 102$110,2012$.

Karmakar, S. and Simonovic, S.: Flood Frequency Analysis Using Copula with Mixed Marginal Distributions, Water Resour. Res. Rep., available at: http://ir.lib.uwo.ca/wrrr/19 (last access: 15 December 2016), 2007.

Katz, R. W. and Brown, B. G.: Extreme events in a changing climate: variability is more important than averages, Climatic Change, 21, 289-302, 1992.

Katz, R. W., Parlange, M. B., and Naveau, P.: Statistics of extremes in hydrology, Adv. Water Resour., 25, 1287-1304, 2002.

Kerr, D.: Some aspects of the geography of finance in Canada, Can. Geogr.-Geogr. Can., 9, 175-192, https://doi.org/10.1111/j.15410064.1965.tb00825.x, 1965.

Knutson, T. R., Zeng, F., and Wittenberg, A. T.: Seasonal and annual mean precipitation extremes occurring during 2013: a US focused analysis, B. Am. Meteorol. Soc., 95, S19-S23, 2014.

Kodra, E. and Ganguly, A. R.: Asymmetry of projected increases in extreme temperature distributions, Sci. Rep.-UK, 4, 5884, https://doi.org/10.1038/srep05884, 2014.

Komi, K., Amisigo, B. A., Diekkrüger, B., and Hountondji, F. C.: Regional flood frequency analysis in the Volta River Basin, West Africa, Hydrology, 3, 5, https://doi.org/10.3390/hydrology30100005, 2016.

Koutsoyiannis, D. and Montanari, A.: Negligent killing of scientific concepts: the stationarity case, Hydrolog. Sci. J., 60, 1174-1183, 2015.

Kumar, D. and Ganguly, A. R.: Intercomparison of model response and internal variability across climate model ensembles, Clim. Dynam., 1-13, https://doi.org/10.1007/s00382-017-39144, 2017.

Kunkel, K. E.: North American trends in extreme precipitation, Nat. Hazards, 29, 291-305, https://doi.org/10.1023/A:1023694115864, 2003.

Kwiatkowski, D., Phillips, P. C., Schmidt, P., and Shin, Y.: Testing the null hypothesis of stationarity against the alternative of a unit root: How sure are we that economic time series have a unit root? J. Econ., 54, 159-178, 1992.

Lapen, D. R. and Hayhoe, H. N.: Spatial analysis of seasonal and annual temperature and precipitation normals in Southern Ontario, Canada, J. Great Lakes Res., 29, 529-544, https://doi.org/10.1016/S0380-1330(03)70457-2, 2003.

Lenderink, G. and van Meijgaard, E.: Increase in hourly precipitation extremes beyond expectations from temperature changes, Nat. Geosci., 1, 511-514, https://doi.org/10.1038/ngeo262, 2008.

Lenderink, G., Barbero, R., Loriaux, J. M., and Fowler, H. J.: SuperClausius-Clapeyron scaling of extreme hourly convective precipitation and its relation to large-scale atmospheric conditions, J. Climate, 30, 6037-6052, https://doi.org/10.1175/JCLI-D-160808.1, 2017.

Li, H., Sheffield, J., and Wood, E. F.: Bias correction of monthly precipitation and temperature fields from Intergovernmental Panel on Climate Change AR4 models using equidistant quantile matching, J. Geophys. Res.-Atmos., 115, D10101, https://doi.org/10.1029/2009JD012882, 2010. 
Lima, C. H., Kwon, H.-H., and Kim, J.-Y.: A Bayesian beta distribution model for estimating rainfall IDF curves in a changing climate, J. Hydrol., 540, 744-756, 2016.

Madsen, H., Arnbjerg-Nielsen, K., and Mikkelsen, P. S.: Update of regional intensity-duration-frequency curves in Denmark: tendency towards increased storm intensities, Atmos. Res., 92, 343349, 2009.

Mailhot, A., Beauregard, I., Talbot, G., Caya, D., and Biner, S.: Future changes in intense precipitation over Canada assessed from multi-model NARCCAP ensemble simulations, Int. J. Climatol., 32, 1151-1163, 2012.

Maraun, D.: Bias correction, quantile mapping, and downscaling: revisiting the inflation issue, J. Climate, 26, 2137-2143, 2013.

Markose, S. and Alentorn, A.: The Generalized Extreme Value (GEV) distribution, implied tail index and option pricing, J. Deriv., 18, 35-60, 2005.

Martins, E. S. and Stedinger, J. R.: Generalized maximumlikelihood generalized extreme-value quantile estimators for hydrologic data, Water Resour. Res., 36, 737-744, 2000.

Meehl, G. A., Goddard, L., Murphy, J., Stouffer, R. J., Boer, G., Danabasoglu, G., Dixon, K., Giorgetta, M. A., Greene, A. M., Hawkins, E., Hegerl, G., Karoly, D., Keenlyside, N., Kimoto, M., Kirtman, B., Navarra, A., Pulwarty, R., Smith, D., Stammer, D., and Stockdale, T.: Decadal prediction, B. Am. Meteorol. Soc., 90, 1467-1485, https://doi.org/10.1175/2009BAMS2778.1, 2009.

Miao, C., Sun, Q., Borthwick, A. G. L., and Duan, Q.: Linkage between hourly precipitation events and atmospheric temperature changes over China during the warm season, Sci. Rep.-UK, 6, srep22543, https://doi.org/10.1038/srep22543, 2016.

Mikkelsen, P. S., Madsen, H., Arnbjerg-Nielsen, K., Rosbjerg, D., and Harremoës, P.: Selection of regional historical rainfall time series as input to urban drainage simulations at ungauged locations, Atmos. Res., 77, 4-17, https://doi.org/10.1016/j.atmosres.2004.10.016, 2005.

Miller, J. D., Kim, H., Kjeldsen, T. R., Packman, J., Grebby, S., and Dearden, R.: Assessing the impact of urbanization on storm runoff in a peri-urban catchment using historical change in impervious cover, J. Hydrol., 515, 59-70, https://doi.org/10.1016/j.jhydrol.2014.04.011, 2014.

Milly, P. C. D., Betancourt, J., Falkenmark, M., Hirsch, R. M., Kundzewicz, Z. W., Lettenmaier, D. P., and Stouffer, R. J.: Stationarity Is Dead: Whither Water Management?, Science, 319, 573-574, https://doi.org/10.1126/science.1151915, 2008.

Mishra, V., Dominguez, F., and Lettenmaier, D. P.: Urban precipitation extremes: How reliable are regional climate models?, Geophys. Res. Lett., 39, L03407, https://doi.org/10.1029/2011GL050658, 2012.

Moglen, G. E. and Schwartz, D. E.: Methods for adjusting US geological survey rural regression peak discharges in an urban setting, US Geological Survey Scientific Investigation Report 20065270, 1-55, 2006.

Mohsin, T. and Gough, W. A.: Characterization and estimation of Urban Heat Island at Toronto: impact of the choice of rural sites, Theor. Appl. Climatol., 108, 105-117, 2012.

Mölders, N. and Olson, M. A.: Impact of urban effects on precipitation in high latitudes, J. Hydrometeorol., 5, 409-429, 2004.

Mondal, A. and Mujumdar, P. P.: Modeling nonstationarity in intensity, duration and frequency of ex- treme rainfall over India, J. Hydrol., 521, 217-231, https://doi.org/10.1016/j.jhydrol.2014.11.071, 2015.

Montanari, A. and Koutsoyiannis, D.: Modeling and mitigating natural hazards: stationarity is immortal!, Water Resour. Res., 50, 9748-9756, 2014.

O'Gorman, P. A.: Precipitation extremes under climate change, Curr. Clim. Change Rep., 1, 49-59, https://doi.org/10.1007/s40641-015-0009-3, 2015.

O'Gorman, P. A. and Schneider, T.: The physical basis for increases in precipitation extremes in simulations of 21 st-century climate change, P. Natl. Acad. Sci. USA, 106, 14773-14777, 2009.

Olsson, J.: Limits and characteristics of the multifractal behaviour of a high-resolution rainfall time series, Nonlinear Proc. Geoph., 2, 23-29, 1995.

Olsson, J.: Evaluation of a scaling cascade model for temporal rain- fall disaggregation, Hydrol. Earth Syst. Sci., 2, 19-30, https://doi.org/10.5194/hess-2-19-1998, 1998.

Paixao, E., Auld, H., Mirza, M. M. Q., Klaassen, J., and Shephard, M. W.: Regionalization of heavy rainfall to improve climatic design values for infrastructure: case study in Southern Ontario, Canada, Hydrol. Sci. J., 56, 1067-1089, https://doi.org/10.1080/02626667.2011.608069, 2011.

Papalexiou, S. M., Koutsoyiannis, D., and Makropoulos, C.: How extreme is extreme? An assessment of daily rainfall distribution tails, Hydrol. Earth Syst. Sci., 17, 851-862, https://doi.org/10.5194/hess-17-851-2013, 2013.

Partridge, M., Olfert, M. R., and Alasia, A.: Canadian cities as regional engines of growth: agglomeration and amenities, Can. J. Econ., 40, 39-68, https://doi.org/10.1111/j.13652966.2007.00399.x, 2007.

Pendergrass, A. G., Lehner, F., Sanderson, B. M., and Xu, Y.: Does extreme precipitation intensity depend on the emissions scenario?, Geophys. Res. Lett., 42, 8767-8774, 2015.

Petrow, T. and Merz, B.: Trends in flood magnitude, frequency and seasonality in Germany in the period 1951-2002, J. Hydrol., 371, 129-141, 2009.

Pettitt, A. N.: A non-parametric approach to the change-point problem, Appl. Statist., 126-135, 1979.

Pfahl, S., O'Gorman, P. A., and Fischer, E. M.: Understanding the regional pattern of projected future changes in extreme precipitation, Nat. Clim. Change, 7, 423-427, https://doi.org/10.1038/nclimate3287, 2017.

Pinheiro, E. C. and Ferrari, S. L. P.: A comparative review of generalizations of the Gumbel extreme value distribution with an application to wind speed data, J. Stat. Comput. Sim., 86, 22412261, https://doi.org/10.1080/00949655.2015.1107909, 2016.

Porporato, A. and Ridolfi, L.: Influence of weak trends on exceedance probability, Stoch. Hydrol. Hydraul., 12, 1-14, 1998.

Prein, A. F., Rasmussen, R. M., Ikeda, K., Liu, C., Clark, M. P., and Holland, G. J.: The future intensification of hourly precipitation extremes, Nat. Clim. Change, 7, 48-52, https://doi.org/10.1038/nclimate3168, 2016.

Prein, A. F., Liu, C., Ikeda, K., Trier, S. B., Rasmussen, R. M., Holland, G. J., and Clark, M. P.: Increased rainfall volume from future convective storms in the US, Nat. Clim. Change, 7, 880-884, https://doi.org/10.1038/s41558-017-0007-7, 2017.

Priestley, M. B. and Rao, T. S.: A test for non-stationarity of timeseries, J. Roy. Stat. Soc. B Met., 31, 140-149, 1969. 
Rana, A., Bengtsson, L., Olsson, J., and Jothiprakash, V.: Development of IDF-curves for tropical india by random cascade modeling, Hydrol. Earth Syst. Sci. Discuss., https://doi.org/10.5194/hessd-10-4709-2013, 2013.

Read, L. K. and Vogel, R. M.: Reliability, return periods, and risk under nonstationarity, Water Resour. Res., 51, 6381-6398, https://doi.org/10.1002/2015WR017089, 2015.

Reddy, M. J. and Ganguli, P.: Spatio-temporal analysis and derivation of copula-based intensity-area-frequency curves for droughts in western Rajasthan (India), Stoch. Env. Res. Risk A., 27, 1975-1989, 2013.

Renard, B., Sun, X., and Lang, M.: Bayesian methods for nonstationary extreme value analysis, in: Extremes in a Changing Climate, Springer, 39-95, 2013.

Rootzén, H. and Katz, R. W.: Design Life Level: quantifying risk in a changing climate, Water Resour. Res., 49, 5964-5972, https://doi.org/10.1002/wrcr.20425, 2013.

Rosner, A., Vogel, R. M., and Kirshen, P. H.: A riskbased approach to flood management decisions in a nonstationary world, Water Resour. Res., 50, 1928-1942, https://doi.org/10.1002/2013WR014561, 2014.

Ross, G. J., Tasoulis, D. K., and Adams, N. M.: Nonparametric monitoring of data streams for changes in location and scale, Technometrics, 53, 379-389, https://doi.org/10.1198/TECH.2011.10069, 2011.

Ruiz-Villanueva, V., Borga, M., Zoccatelli, D., Marchi, L., Gaume, E., and Ehret, U.: Extreme flood response to short-duration convective rainfall in South-West Germany, Hydrol. Earth Syst. Sci., 16, 1543-1559, https://doi.org/10.5194/hess-16-1543-2012, 2012.

Sadri, S., Kam, J., and Sheffield, J.: Nonstationarity of low flows and their timing in the eastern United States, Hydrol. Earth Syst. Sci., 20, 633-649, https://doi.org/10.5194/hess-20-6332016, 2016.

Sanderson, M. and Gorski, R.: The effect of metropolitan DetroitWindsor on precipitation, J. Appl. Meteorol., 17, 423-427, 1978.

Sandink, D., Simonovic, S. P., Schardong, A., and Srivastav, R.: A decision support system for updating and incorporating climate change impacts into rainfall intensity-duration-frequency curves: Review of the stakeholder involvement process, Environ. Modell. Softw., 84, 193-209, 2016.

SC (Statistics Canada): 2011 Census - Boundary files, Government of Canada, available at: http://www12. statcan.gc.ca/census-recensement/2011/geo/bound-limit/ bound-limit-2011-eng.cfm, last access: November 2016.

Schaller, N., Kay, A. L., Lamb, R., Massey, N. R., van Oldenborgh, G. J., Otto, F. E. L., Sparrow, S. N., Vautard, R., Yiou, P., Ashpole, I., Bowery, A., Crooks, S. M., Haustein, K., Huntingford, C., Ingram, W. J., Jones, R. G., Legg, T., Miller, J., Skeggs, J., Wallom, D., Weisheimer, A., Wilson, S., Stott, P. A., and Allen, M. R.: Human influence on climate in the 2014 southern England winter floods and their impacts, Nat. Clim. Change, 6, 627-634, 2016.

Schroeer, K. and Kirchengast, G.: Sensitivity of extreme precipitation to temperature: the variability of scaling factors from a regional to local perspective, Clim. Dynam., 1-14, https://doi.org/10.1007/s00382-017-3857-9, 2017.

Sarhadi, A. and Soulis, E. D.: Time-varying extreme rainfall intensity-duration-frequency curves in a chang- ing climate, Geophys. Res. Lett., 44, 2454-2463, https://doi.org/10.1002/2016GL072201, 2017.

Serinaldi, F. and Kilsby, C. G.: Stationarity is undead: Uncertainty dominates the distribution of extremes, Adv. Water Resour., 77, 17-36, 2015

Serinaldi, F. and Kilsby, C. G.: The importance of prewhitening in change point analysis under persistence, Stoch. Env. Res. Risk A., 30, 763-777, https://doi.org/10.1007/s00477-015-10415,2016

Serinaldi, F., Kilsby, C. G., and Lombardo, F.: Untenable nonstationarity: An assessment of the fitness for purpose of trend tests in hydrology, Adv. Water Resour., 111, 132-155, https://doi.org/10.1016/j.advwatres.2017.10.015, 2018.

Shabbar, A., Bonsal, B., and Khandekar, M.: Canadian precipitation patterns associated with the Southern Oscillation, J. Climate, 10, 3016-3027, 1997.

Shaw, S. B., Royem, A. A., and Riha, S. J.: The relationship between extreme hourly precipitation and surface temperature in different hydroclimatic regions of the United States, J. Hydrometeorol., 12, 319-325, 2011.

Shephard, M. W., Mekis, E., Morris, R. J., Feng, Y., Zhang, X., Kilcup, K., and Fleetwood, R.: Trends in Canadian short-duration extreme rainfall: including an intensity-duration-frequency perspective, Atmos. Ocean, 52, 398-417, 2014.

Simonovic, S. P. and Peck, A.: Updated rainfall intensity duration frequency curves for the City of London under the changing climate, Department of Civil and Environmental Engineering, The University of Western Ontario, available at: http://ir.lib.uwo.ca/ wrrr/29/ (last access: 13 January 2017), 2009.

Singh, J., Vittal, H., Karmakar, S., Ghosh, S., and Niyogi, D.: Urbanization causes nonstationarity in Indian Summer Monsoon Rainfall extremes, Geophys. Res. Lett., 43, 11269-11277, https://doi.org/10.1002/2016GL071238, 2016.

Stocker, T. F., Qin, D., Plattner, G. K., Tignor, M., Allen, S. K., Boschung, J., Nauels, A., Xia, Y., Bex, V., and Midgley, P. M.: Climate change 2013: the physical science basis. Intergovernmental panel on climate change, Working Group I Contribution to the IPCC Fifth Assessment Report (AR5), New York, 2013.

Svensson, C. and Jones, D. A.: Review of rainfall frequency estimation methods, J. Flood Risk Manag., 3, 296-313, 2010.

Switzman, H., Razavi, T., Traore, S., Coulibaly, P., Burn, D. H., Henderson, J., Fausto, E., and Ness, R.: Variability of future extreme rainfall statistics: comparison of multiple IDF projections, J. Hydrol. Eng., 22, 04017046, https://doi.org/10.1061/(ASCE)HE.1943-5584.0001561, 2017.

Teutschbein, C. and Seibert, J.: Bias correction of regional climate model simulations for hydrological climate-change impact studies: Review and evaluation of different methods, J. Hydrol., 456, 12-29, 2012.

TRCA (Toronto Region Conservation Authority): Resilient City: Preparing for Extreme Weather Events, City of Toronto, Canada, 2013.

Towler, E., Rajagopalan, B., Gilleland, E., Summers, R. S., Yates, D., and Katz, R. W.: Modeling hydrologic and water quality extremes in a changing climate: a statistical approach based on extreme value theory, Water Resour. Res., 46, W11504, https://doi.org/10.1029/2009WR008876, 2010.

Trenberth, K. E.: Atmospheric moisture recycling: role of advection and local evaporation, J. Climate, 12, 1368-1381, 1999. 
Van Gelder, P., Wang, W., and Vrijling, J. K.: Statistical estimation methods for extreme hydrological events, in Extreme Hydrological Events: New Concepts for Security, Springer, 2006.

Villarini, G., Serinaldi, F., Smith, J. A., and Krajewski, W. F.: On the stationarity of annual flood peaks in the continental United States during the 20th century, Water Resour. Res., 45, W08417, https://doi.org/10.1029/2008WR007645, 2009a.

Villarini, G., Smith, J. A., Serinaldi, F., Bales, J., Bates, P. D., and Krajewski, W. F.: Flood frequency analysis for nonstationary annual peak records in an urban drainage basin, Adv. Water Resour., 32, 1255-1266, https://doi.org/10.1016/j.advwatres.2009.05.003, 2009b.

von Storch, H. and Navarra, A.: Analysis of Climate Variability: Applications of Statistical Techniques, Springer, 1-303, 1999.

Wasko, C. and Sharma, A.: Steeper temporal distribution of rain intensity at higher temperatures within Australian storms, Nat. Geosci., 8, 527-529, 2015.

Wasko, C. and Sharma, A.: Continuous rainfall generation for a warmer climate using observed temperature sensitivities, J. Hydrol., 544, 575-590, 2017.

Wang, X., Huang, G., Liu, J., Li, Z., and Zhao, S.: Ensemble projections of regional climatic changes over Ontario, Canada, J. Climate, 28, 7327-7346, 2015.

Westra, S. and Sisson, S. A.: Detection of non-stationarity in precipitation extremes using a max-stable process model, J. Hydrol., 406, 119-128, 2011.

Westra, S., Alexander, L. V., and Zwiers, F. W.: Global increasing trends in annual maximum daily precipitation, J. Climate, 26, 3904-3918, https://doi.org/10.1175/JCLI-D-12-00502.1, 2012.

Wilson, P. S. and Toumi, R.: A fundamental probability distribution for heavy rainfall, Geophys. Res. Lett., 32, L14812, https://doi.org/10.1029/2005GL022465, 2005.
Xie, H., Li, D., and Xiong, L.: Exploring the ability of the Pettitt method for detecting change point by Monte Carlo simulation, Stoch. Env. Res. Risk A., 28, 1643-1655, 2014.

Yilmaz, A. G. and Perera, B. J. C.: Extreme rainfall nonstationarity investigation and intensity-frequency-duration relationship, J. Hydrol. Eng., 19, 1160-1172, 2013.

Yilmaz, A. G., Hossain, I., and Perera, B. J. C.: Effect of climate change and variability on extreme rainfall intensity-frequencyduration relationships: a case study of Melbourne, Hydrol. Earth Syst. Sci., 18, 4065-4076, https://doi.org/10.5194/hess-18-40652014, 2014.

Yilmaz, A. G., Imteaz, M. A., and Perera, B. J. C.: Investigation of non-stationarity of extreme rainfalls and spatial variability of rainfall intensity-frequency-duration relationships: a case study of Victoria, Australia, Int. J. Climatol., 37, 430-442, https://doi.org/10.1002/joc.4716, 2017.

Yiou, P. and Cattiaux, J.: Contribution of atmospheric circulation to wet north European summer precipitation of 2012, B. Am. Meteorol. Soc., 94, S39, 2013.

Yue, S. and Wang, C. Y.: Power of the Mann-Whitney test for detecting a shift in median or mean of hydro-meteorological data, Stoch. Env. Res. Risk A., 16, 307-323, 2002.

Yue, S., Pilon, P., Phinney, B., and Cavadias, G.: The influence of autocorrelation on the ability to detect trend in hydrological series, Hydrol. Process., 16, 1807-1829, 2002.

Yue, S., Pilon, P., and Phinney, B. O. B.: Canadian streamflow trend detection: impacts of serial and cross-correlation, Hydrol. Sci. J., 48, 51-63, 2003. 